\title{
\$1.25 Trillion is Still Real Money: Some Facts About the Effects of the Federal Reserve's Mortgage Market Investments
}

\author{
Andreas Fuster and Paul S. Willen
}

\begin{abstract}
:
This paper measures the effects on the primary U.S. mortgage market of the large-scale asset purchase (LSAP) program in which the Federal Reserve bought \$1.25 trillion of mortgagebacked securities in 2009 and 2010. We use an event-study approach and measure the movements in both prices and quantities around the initial announcement of the LSAP and subsequent changes to the program. We use a new dataset to document the changes in the menu of rates and points offered to borrowers and show that there was wide dispersion in the rate changes generated by the announcement of the LSAP program, with some borrowers seeing immediate rate reductions of up to 40 basis points and other borrowers confronting rate increases. We show that the LSAP program led to a substantial boost in market activity, with discontinuous increases in searches, applications, and originations for refinance mortgages but not for purchase mortgages. Finally, we show that more creditworthy borrowers were significantly more likely to benefit from the improved credit availability.
\end{abstract}

\section{JEL Classifications: E5, E21, G21}

Andreas Fuster is a graduate student in the economics department at Harvard University and a graduate fellow in the research department at the Federal Reserve Bank of Boston. His e-mail address is afuster@fas.harvard.edu. Paul S. Willen is a Senior Economist and Policy Advisor at the Federal Reserve Bank of Boston. His e-mail address is paul.willen@bos.frb.org

This paper, which may be revised, is available on the web site of the Federal Reserve Bank of Boston at http://www.bos.frb.org/economic/wp/index.htm.

The authors thank Zack Kimball for stellar research assistance, Glenn Canner for help with the HMDA data, and Gene Amromin, Daniel Cooper, Scott Frame, Jeff Fuhrer, David Romer, Bruce Backer and Craig Doriot of LoanSifter, Ben Niles and Andrew Pfeifer of Merrimack Mortgage Company, Adam Quinones of Mortgage News Daily, and Kurt Strandson of Radiant Mortgage for helpful discussions and suggestions.

The views expressed in this paper are those of the authors and do not necessarily represent those of the Federal Reserve Bank of Boston or the Federal Reserve System.

This version: November 18, 2010 
"A billion here, a billion there - pretty soon, you're talking real money."

Attributed to Senator Everett Dirksen 1

\section{Introduction}

On November 25, 2008, the Federal Open Market Committee (FOMC) announced a plan for the Federal Reserve Bank of New York to purchase $\$ 500$ billion dollars of mortgage-backed securities (MBS) issued by the two main government-sponsored entities (GSEs) for housing, Fannie Mae and Freddie Mac, as well as ones guaranteed by the government agency Ginnie Mae. The purpose of the so-called large-scale asset purchase (LSAP) program was to reduce the spread between mortgage interest rates and other interest rates of similar duration. In its initial press release, the FOMC said:

Spreads of rates on GSE debt and on GSE-guaranteed mortgages have widened appreciably of late. This action is being taken to reduce the cost and increase the availability of credit for the purchase of houses, which in turn should support housing markets and foster improved conditions in financial markets more generally 2

The FOMC expanded the LSAP program in March 2009, and overall the Federal Reserve purchased $\$ 1.25$ trillion of agency MBS between January 5, 2009 and March 31, 2010, the program's official end date. In addition to the MBS purchases, the Fed also purchased $\$ 175$ billion of GSE debt and $\$ 300$ billion of Treasury securities. As Gagnon et al. (2010) report, this corresponds to about 22 percent of the total outstanding stock of these securities at the beginning of the LSAP program, indicating the substantial size of the intervention.

Yet beyond anecdotal evidence, relatively little is know about the effects the LSAPs had on the economy in general and on the mortgage market in particular. Gagnon et al. (2010) provide an excellent description of the theoretical channels through which the LSAP program could affect the mortgage market, and how it was implemented. Furthermore, they provide a series of event studies of the effect various LSAP announcements had on the yields in the secondary mortgage market and other interest rates. Gagnon et al. report that during one-day windows across the eight announcements included in their "baseline event set," current-coupon agency MBS yields fell by a cumulative 113 basis points 3

\footnotetext{
${ }^{1}$ There is some doubt about the true provenance of the remark. See http://www.dirksencenter.org/print_emd_billionhere.htm.

${ }^{2} \mathrm{http}$ ://www.federalreserve.gov/newsevents/press/monetary/20081125b.htm.

${ }^{3}$ Their baseline event set includes November 25, 2008 (initial announcement), December 1, 2008 (Chairman speech), and the FOMC Statements on January 28, March 18, August 12, September 23, and November 2,2009 .
} 
In this paper, we present evidence that shows that the LSAP program had immediate and large effects on credit availability to borrowers in the primary mortgage market. We innovate along two dimensions. First, as far as prices go, we focus on shifts in the entire menu of options available to prospective borrowers, rather than on a single interest rate. To do so, we rely on a new dataset obtained from LoanSifter, a firm which provides mortgage brokers with electronic access to lender rate sheets. We use daily data on loan offers made by lenders over the period from October 2008 to February 2009, which captures credit conditions prevailing before and after the initial LSAP announcement. Second, unlike previous researchers, we also look at quantities, not just prices. Using a variety of data sources, we measure how many borrowers searched for loans, applied for loans, were rejected for loans, and received loans immediately before and after the LSAP program was announced, as well as further along into the program. In addition, our micro-level data allows us to examine whether the characteristics of borrowers who shopped for and obtained mortgages were different before and after the LSAP announcement.

Our analysis yields three main findings. First, the announcement of the LSAP program almost immediately led to significant reductions in interest rates for borrowers. Measuring how much rates decreased is far more difficult than it might sound because there was wide variation in the size of the reduction across borrowers and loans. A borrower's credit score, loan-to-value ratio, other characteristics of the loan or the property, as well as whether the borrower wanted to pay discount points or receive money from the lender to cover closing costs - all these factors matter for the extent of the interest rate change. In the example we focus on, the changes in rates accompanying the LSAP announcement ranged from a reduction of 41 basis points to an increase of 10 basis points. In other words, for some borrowers, the LSAP announcement was a boon while for other very similar and sometimes even observationally equivalent borrowers, the LSAP announcement was irrelevant.

We find that in the days after November 25, the reduction in rates available to borrowers was more pronounced for loans in which borrowers paid discount points compared to loans in which borrowers expected the lender to pay money to cover the closing costs. In our data, a prototypical borrower who expected to pay one point at closing saw the interest rate fall by 60 basis points (on average across the lenders in our data) between November 24 and December 4 whereas a borrower who expected the lender to pay him one point at closing (which could be used to cover closing costs) saw the rate fall by only 16 basis points. This asymmetry became more pronounced over time: by the first week of January 2009, the average rate differential obtained by paying one discount point instead of receiving one point had gone up to almost 120 basis points, compared to 70 basis points in the weeks before the LSAP program was announced. As we will discuss, this also means that borrowers with poor credit, who are required to pay additional points when closing a mortgage, benefited 
less in terms of rate reductions than borrowers with very good credit.

Second, the Fed's initial announcement led to an immediate and large increase in borrower activity in the primary loan market. LoanSifter provides records of the number of searches for loan offers that brokers made on behalf of borrowers. The records show an increase of approximately 300 percent in the number of borrowers shopping for refinance mortgages on November 25 compared to preceding days. The non-public-use HMDA data file, which contains the dates of applications, shows that this increase in shopping activity translated into a 150-250 percent increase in the number of applications and subsequent originations. These increases in activity persisted and peaked in mid-December and early January, and then again after the extension of the LSAP program was announced on March 18, 2009. The HMDA data also show that the percentage of applications turning into originated mortgages discontinuously increased after the LSAP announcement, meaning that looking only at an index of applications would lead one to underestimate the program's true effects on the U.S. mortgage market. The HMDA data further reveal that the time between application and origination increased significantly in the months after the announcement, thereby validating contemporary anecdotal evidence that lenders were having trouble processing the increased volume of applications.

The effects of the LSAP program announcement do not carry over into the purchase mortgage market, since the announcement appears to have had little effect on the distribution or the number of purchase mortgage applications or originations. Perhaps more surprisingly, the LoanSifter data show little effect even on search activity, suggesting that the program announcement did not lead to increased interest in home buying.

Third, the initial LSAP announcement generated a significant shift in the characteristics of borrowers. In particular, refinancing activity became highly skewed toward borrowers with high credit scores. We see this shift by using a matched sample of loans from LPS, a loanlevel dataset, and HMDA, which allows us to determine the application date of originated mortgages. Comparing the day before the initial LSAP announcement on November 25 to the day after, we see a bit more than a doubling in the number of refinance applications that led to origination for borrowers with FICO scores below 700. For borrowers with FICO scores between 700 and 720, that number more than tripled, for those between 720 and 740, it quadrupled, for those between 740 and 760, activity quintupled, and for those above 760, activity went up more than seven-fold. These differences in refinancing activity between different borrower types persisted further into the program - for instance, the bottom 25th percentile of FICO scores for successful mortgage refinance applicants was about 50 points higher in the first four months of 2009 than in the months before the LSAP program's announcement. 
One potential explanation for this skewed distribution is that lenders rejected applications from borrowers with low FICO scores, but the HMDA data show that this is unlikely to explain all of the change. While HMDA does not collect FICO scores, it does collect applicant income, and we show that denial rates decreased after the LSAP announcement for all income categories. Another possibility is that borrowers with low FICO scores pay less attention to improved refinancing possibilities, so that they did not even consider refinancing. Based on the LoanSifter search data, we do find a somewhat stronger increase in search activity among borrowers with high FICO scores, but the difference is too small to explain the large shift in the FICO distribution of originated mortgages.

We instead argue that an important driver behind the overrepresentation of high credit scores among refinancing borrowers involves the presence of additional fees, known as LoanLevel Price Adjustments or Postsettlement Delivery Fees, charged by the GSEs to borrowers with low FICO scores. We show that the relationship between credit scores and refinancing after the LSAP program's announcement was not smooth but displays discontinuities that coincide exactly with increases in fees charged to borrowers. These fees may have had a particularly large impact because they interact with the change in the shape of the available rate-point menu discussed above, which made the financing of these fees through a higher rate relatively more expensive. As a consequence, many borrowers with low FICO scores may simply not have had enough of a financial incentive to refinance.

Our results have important policy implications. The announcement and implementation of the LSAP program had large effects on U.S. mortgage prices and jumpstarted activity in the primary mortgage market, which had almost come to a halt over the second half of 2008 despite the fact that during that time long-term interest rates were very low by historical standards. Furthermore, consumer activity increased almost instantaneously after the announcements - one can even see in the data the difference between the effect of the initial announcement on November 25, which occurred at 8:15 a.m. EST in the morning, and the extension announcement on March 18, which occurred at 2:15 p.m. EST in the afternoon. There are no "long and variable lags" here. This stands in contrast to other consumer-targeted policy like tax cuts, where the effects appear to emerge only when the policy is actually implemented.

That said, our results raise questions about how effectively the LSAP program achieved two of what were widely perceived to be its ultimate objectives: stimulating consumption and stabilizing house prices. On the consumption front, the data suggest that most of the borrowers who took advantage of the opportunities resulting from the LSAP program to refinance their existing mortgages were highly creditworthy, hence unlikely to be credit constrained, and consequently unlikely to have used the cash flow freed up by their reduced mortgage payments to increase consumption spending. 
Assessing the program's potential effect on U.S. house prices is far more difficult because there are many channels through which house prices might have been affected, none of which are particularly well understood. At a basic level, counting the number of purchase mortgages tells us nothing more than we would learn from examining the number of sales. Furthermore, the length and complexity of the purchase process compared to refinancing an existing mortgage would lead us to expect differential lags in the response to easier access to credit. That said, there are several indicators that might suggest a positive effect of the LSAPs on the purchase market: a change in search activity, meaning that more households are considering a purchase, an increase in loan amounts, or a change in the composition of buyers. However, the data show no evidence of any of the above.

We proceed as follows. In the remainder of this section, we provide a brief literature review covering the narrow question of the success of the LSAP program and the slightly broader issue of measuring the success of financial market interventions in the current crisis. In section 2, we review the events that led to the creation of the LSAP program. Sections 3 and 4 describe our data and our findings respectively. In section 5, we speculate on the ways in which the LSAPs affected or may have affected the broader U.S. economy. Section 6] concludes with a discussion of some open questions raised by our analysis.

\subsection{Literature Review}

In a recent working paper, Stroebel and Taylor (2009) argue that the LSAP program failed to achieve its goal, writing that they "find evidence of statistically insignificant or small effects of the program" (p. 1). The canonical regression in the paper has a time series of the spread between a measure of the mortgage interest rate over some riskless rate on the lefthand side and some measure of the LSAPs along with controls on the right-hand side. The authors focus on correcting for changes in prepayment risk and default risk over time, which might confound the effects of the LSAPs on interest rate spreads. Their findings actually display large amounts of variation, with some specifications showing that the LSAP program generates as much as a 30 basis point reduction in spreads. Our approach differs in that we attempt to address the problem of confounding variables by looking at a short time period preceding and following the program's announcement date, we use a much richer dataset, and we look at quantities as well as prices.

As mentioned above, Gagnon et al. (2010) also evaluate the effects of the LSAP program but focus entirely on its effect on securities prices. Our focus is on its effect on households and, in that sense, the papers complement each other. Taylor and Williams (2009) and Duygan-Bump et al. (2010) focus on Federal Reserve facilities set up during the crisis with the former examining the Term Auction Facility (TAF) and the latter focusing on the Asset-Backed Commercial Paper Money Market Fund Liquidity Facility (AMLF). 
Tavlor and Williams (2009) find that the TAF was ineffective while Duygan-Bump et al. (2010) find that the AMLF lowered spreads paid by issuers in the asset-backed commercial paper market.

\section{Events in the Mortgage Market in Late Fall 2008 and Winter 2009}

Policymakers created the LSAP program to respond to two different issues that had emerged in the wake of the financial crisis triggered by the Lehman Brothers bankruptcy in midSeptember 2008. The first issue was macroeconomic stability. Even before Lehman's collapse, monetary policy had turned strongly expansionary as successive cuts had taken the federal funds rate to 2 percent at the beginning of September 2008, down from 5.25 percent a year earlier. In the wake of Lehman's failure, the FOMC made two 50 basis point cuts, on October 8 and October 28 respectively, so that the federal funds rate stood at 1 percent at the beginning of November 2008.

By that time, fears were growing that the economy, which had been weak to begin with, had taken a turn for the worse in the fall. Subsequent data would vindicate those fears, as payroll employment had racked up record reductions every month, with revised data now showing a net loss of 554,000 jobs in October and 728,000 in November 2008.

In addressing the crisis, policymakers were vexed by the broad issue of traditional monetary policy's ineffectiveness amid a collapsing financial system and by the specific problem of the zero lower bound on interest rates - which meant that that there was little room for the FOMC to cut the federal funds rate any further. Some suggested that the FOMC turn to alternative tools. Minutes of the October 28-29, 2008 FOMC meeting, released on November 19, illustrate this tension:

Some members were concerned that the effectiveness of cuts in the target federal funds rate may have been diminished by the financial dislocations, suggesting that further policy action might have limited efficacy in promoting a recovery in economic growth. And some also noted that the Committee had limited room to lower its federal funds rate target further and should therefore consider moving slowly. However, others maintained that the possibility of reduced policy effectiveness and the limited scope for reducing the target further were reasons for a more aggressive policy adjustment; an easing of policy should contribute to a beneficial reduction in some borrowing costs, even if a given rate reduction currently would elicit a smaller effect than in more typical circumstances, and 
more aggressive easing should reduce the odds of a deflationary outcome 4

Several FOMC members had well-known views on the issue of zero nominal bounds and, in fact, the Chairman had raised the purchase of GSE debt as one possible approach to addressing it. In a controversial and widely reported speech in 2002, then-Governor Bernanke had argued against the idea that monetary policy would lose its effectiveness when the federal funds rate approached zero, and discussed specific options for "alternative" monetary policy, one of which was to invest in securities issued by the agencies-Fannie Mae, Freddie Mac, and Ginnie Mae:

Yet another option [to stimulate the economy] would be for the Fed to use its existing authority to operate in the markets for agency debt 5

The other main issue was that the secondary mortgage market was in deep trouble. Ironically, given the widely held belief that securitization had caused the crisis, households were actually more dependent than ever on investors for obtaining their housing finance, since nearly 90 percent of loans originated in fall 2008 were securitized 6 But the market did not appear to be functioning well in part because the nationalization of the two main securitizers had not resolved questions about their long-term viability. Policymakers were well aware of these problems. In an October 15 speech, Fed Chairman Bernanke said that:

[G-7 finance ministers] further agreed that we would take all necessary steps to unfreeze interbank and money markets, and that we will act to restart the secondary markets for mortgages and other securitized assets.7

In addition, some influential voices outside the government had raised the issue of problems in the mortgage market and advocated government investment. In an op-ed essay in the Wall Street Journal early in October and in an accompanying research paper, Glenn Hubbard and Chris Mayer argued that liquidity issues had driven the spread between mortgages and government debt 100 points higher than normal and they advocated that:

the Bush administration and Congress allow all residential mortgages on primary residences to be refinanced into 30-year fixed-rate mortgages at 5.25\% (matching the lowest mortgage rate in the past 30 years), and place those mortgages with Fannie Mae and Freddie Mac. 8

\footnotetext{
${ }^{4}$ http://federalreserve.gov/monetarypolicy/fomcminutes20081029.htm. 5 http://federalreserve.gov/boarddocs/speeches/2002/20021121/default.htm.

${ }^{6}$ The October 31, 2008 issue of Inside Mortgage Finance reported that Fannie Mae, Freddie Mac, the Federal Housing Administration (FHA), and the Department of Veterans Affairs (VA) accounted for $\$ 262$ billion of $\$ 300$ billion of originations the 3rd quarter of 2008 .

${ }^{7}$ http://federalreserve.gov/newsevents/speech/bernanke20081015a.htm

${ }^{8}$ R. Glenn Hubbard and Chris Mayer, "First, Let's Stabilize Home Prices," 2 October 2008, The Wall Street Journal. The paper appeared as Hubbard and Maver (2009).
} 
They justified the intervention both for its direct effect on the housing market:

Foreclosures are accelerating. House prices continue to fall, weakening household balance sheets and the balance sheets of financial institutions. But this can stop. The price of a home is partially dependent on the mortgage rate - a lower mortgage rate raises house prices.

and on the macroeconomy in general:

Improvements in household and financial institution balance sheets will increase investment and consumer spending, which will mitigate the extent of the current downturn.

In sum, by the beginning of November 2008, the idea that the Fed would use its balance sheet to invest in mortgage-backed securities was in the air, both as a way of stabilizing the housing market and stimulating the macroeconomy. There was, however, no public statement by any voting or non-voting member of the FOMC or other Federal Reserve System official suggesting that the FOMC was seriously contemplating the LSAPs and, in that sense, the program's announcement on November 25 seems to be have been something of a surprise.

The LSAP program was not the only thing happening in financial markets in November 2008. Over the course of the month, 10-year treasury yields fell from close to 4 percent to less than 3 percent, the lowest in at least 50 years. One possible explanation for this drop is that investors had begun to anticipate more forceful action from the FOMC. Another related possibility is that the drumbeat of bad macroeconomic news was becoming louder and increasingly difficult to ignore. Initial claims for jobless benefits, which had fluctuated between 400,000 and 500,000 over the previous six months, crossed 500,000 for the first time in early November. The Institute for Supply Management (ISM) index fell from 50.1 in August, indicating expansion, to 37.1 in November, indicating contraction. The Conference Board's consumer confidence index fell from almost 60 in August to under 40 in October.

When announcing the LSAP program, the FOMC justified its action largely as a measure to assist the U.S. housing market and financial markets in general; it did not explicitly mention broader macroeconomic goals:

This action is being taken to reduce the cost and increase the availability of credit for the purchase of houses, which in turn should support housing markets and foster improved conditions in financial markets more generally 9

However, Federal Reserve officials were unequivocal in their view that the LSAP program was part of a broader effort to stimulate the economy. In an October 9, 2009 speech, Vice Chairman Kohn stated that:

${ }^{9}$ http://federalreserve.gov/newsevents/press/monetary/20081125b.htm. 
Our purchases of longer-term Treasury, agency, and agency-guaranteed mortgagebacked securities were undertaken to support aggregate demand 10

The belief that stimulating aggregate demand and, more specifically, consumer spending was the main goal of the program was widely held. As one reporter described it shortly after the initial announcement:

By stimulating a home refinancing wave, the Fed can redirect cash currently tied up in mortgage payments to the economy. Lower rates can have an indirect effect of at least slowing home price declines, said Keith Gumbinger, vice president at HSH Associates, a Pompton Plains, New Jersey, data company.

"If you don’t have to send $\$ 1,000$ a month to your mortgage lender but only $\$ 900$, you've got $\$ 100$ a month to go stimulate the economy," Gumbinger said. "That's probably as, if not more important, than stimulating home buying."11

The initial program announcement provided minimal details about the LSAPs. For our purposes, the only important point was that the purchases would start almost immediately:

Purchases of up to $\$ 500$ billion in MBS will be conducted by asset managers selected via a competitive process with a goal of beginning these purchases before year-end.

More details of the LSAP program were issued on December 30, 2008 including a FAQ in which the Federal Reserve Bank of New York said that purchases would actually begin in early January; in fact, the first purchases occurred on January 5. There was no discussion in the initial announcement or the FAQ of exactly which securities would be purchased.

The initial LSAPs were confined to agency securities but that fact did not eliminate the idea that the Fed would also invest in long-dated government securities. Over the period in which the New York Fed implemented the LSAPs, Federal Reserve officials signaled more and more clearly that they planned to take precisely that action. On December 1, 2008, Chairman Bernanke gave a speech in which he broached the idea that "the Fed could purchase longerterm Treasury or agency securities on the open market in substantial quantities."12 In its December 16 statement, the FOMC said that it was "evaluating the potential benefits of purchasing longer-term Treasury securities." 13 Both of these announcements led to reductions in already low rates on long-dated treasury notes.

\footnotetext{
${ }^{10}$ http://federalreserve.gov/newsevents/speech/kohn20091009a.htm.

${ }^{11} \mathrm{Al}$ Yoon and Lynn Adler, "Fed Engineers U.S. Mortgage Rate Cut," Reuters, November $26,2008$. Available at http://www.reuters.com/article/idUSTRE4AP40Y20081126

${ }^{12}$ http://federalreserve.gov/newsevents/speech/bernanke20081201a.htm.

${ }^{13}$ http://federalreserve.gov/newsevents/press/monetary/20081216b.htm
} 
In light of economy's continuing deterioration, the FOMC announced in March 2009 that it would expand the mortgage component of the LSAP program from $\$ 500$ billion to $\$ 1.25$ trillion. In addition, the FOMC decided that the benefits outweighed the costs and announced that it would purchase $\$ 300$ billion of longer-term Treasury securities, as well as $\$ 175$ billion of agency debt. These purchases were made throughout 2009 and early 2010, until the LSAP program officially ended on March 31, 2010.

In this study, we will mainly focus on the responses of prices and quantities in the mortgage market immediately around the initial and successive announcements of the LSAP program, based on the assumption that those responses largely reflect the anticipated direct effect of the Fed's purchases of MBS. Another possibility, however, is that the LSAP announcements signaled to markets that the FOMC was ready to take drastic actions and thereby changed the anticipated path of future interest rates. Gagnon et al. (2010) address this question and argue that there is little evidence that the program announcements had such an indirect effect:

Little of the observed declines in longer-term yields appears to reflect declining expectations of future short-term interest rates associated with FOMC communications about the likely future path of the federal funds rate. (p. 21)

\section{Data}

We use three datasets to measure the effects of the LSAP_LoanSifter, HMDA, and LPS. As explained below, each provides a different view of the primary mortgage market during the time of the announcement and implementation of the LSAP program.

\subsection{LoanSifter}

Our data on rate offers and searches come from LoanSifter, which describes itself as:

a proprietary online search engine designed to help mortgage brokers and lenders be more efficient and cost-effective in making the right match between loan programs and those who need them. ... [LoanSifter's] proprietary software is designed to search all of the major lending sources and provides real-time, daily information, fresh from each source 14

LoanSifter's underlying data come from the rate sheets provided by lenders. Historically, these were faxed from lenders to brokers on a daily or even more frequent basis, but now come via e-mail or are posted on lender websites. LoanSifter parses the information from

\footnotetext{
${ }^{14}$ https : //www. loansifter. com/company.aspx.
} 
the source and integrates it into a relational database that allows a broker to search using, among other variables:

\begin{tabular}{lll}
\hline \hline Loan amount & Loan-to-value ratio (LTV) & Cumulative LTV (all liens) \\
FICO & Debt-to-income ratio & Documentation type \\
State & Loan type (fixed, ARM, balloon) & Terms (15 years, 30 years, etc.) \\
Prepayment penalty & Lock period & Property type \\
Purpose (purchase, refi) & Owner-occupied or investment & \\
\hline \hline
\end{tabular}

The broker either specifies a desired number of discount points (that is, the minimum number of points that the broker or the borrower require; if this number is negative, it is the number of points the borrower is willing to pay, with each point corresponding to 1 percent of the loan amount) and receives offers for various rates, or the broker specifies a desired rate and receives offers of various numbers of discount points 15 Each broker (or brokerage) has access to a subset of lenders with which the broker or brokerage has an agreement, and loan offers for an identical loan may differ across brokers for a given lender. On average, the brokers in our sample have access to about 20 lenders, though there is considerable variation.

Our current dataset consists of LoanSifter's daily database backup for each evening from October 16, 2008 to February 9, 2009 (excluding December 8 to 14, during which time backups were unavailable). The dataset contains loan offers from over 140 lenders. Some brokers and lenders are not present over the entire period as they may have joined or left LoanSifter's pool at some point during the sample period. We do not have names of the brokers or lenders, but they have been assigned unique numerical identifiers so we can follow a given broker or lender over time. The data comes in the form of a large relational database; to access loan offers, we "pose" as a certain broker and access the offers this broker would have received for a given search request (that is, certain borrower and loan characteristics) from all the lenders with which the broker had an agreement.

One missing piece of information in this data are the fees that the lenders charge to originate a loan. Industry sources tell us that these fees are changed very rarely, which means that we do not have a problem interpreting the time series since the relative appeal of two different lenders, even if they charge different fees, should be the same over time.

\subsubsection{Data on Actual Searches}

In addition to the data on loan offers, for the timespan from January 1, 2008 to April 9, 2009 we also have the history of actual searches conducted by brokers via the LoanSifter search engine and, after February 2009, by borrowers directly via a consumer website (the Zillow.com Mortgage Marketplace). For each query made to LoanSifter's database, we see

\footnotetext{
${ }^{15}$ See section 4.1 for an explanation of discount points.
} 
the borrower and loan characteristics, as well as the best offer received by the broker (either the lowest rate for a given number of points or the highest number of points for a given rate, depending on which the broker requested) 16

We do not have information about whether the borrower actually applied for or received a loan. We do, however, clean the data to eliminate searches by a given broker for the same borrower on the same day 17 Another complication is that more and more brokers adopted LoanSifter during our sample period; to make sure that our findings are not confounded by this wider use, our analysis only uses brokers who had used LoanSifter for the first time before October 1, 2008.

LoanSifter is based in Wisconsin, but the company operates nationally. As the following table shows, California accounts for a disproportionate share of the searches in our data. However, this does not drive our results, which are robust to removing California.

\begin{tabular}{lcc}
\hline \hline State & $\begin{array}{c}\text { Number of } \\
\text { Searches }\end{array}$ & $\begin{array}{c}\text { Percent of } \\
\text { All Searches }\end{array}$ \\
\hline California & 257,371 & 45.91 \\
Illinois & 37,846 & 6.75 \\
Colorado & 27,076 & 4.83 \\
Georgia & 27,004 & 4.82 \\
Massachusetts & 21,947 & 3.92 \\
\hline Washington & 21,901 & 3.91 \\
Texas & 19,460 & 3.47 \\
Florida & 19,083 & 3.40 \\
North Carolina & 17,979 & 3.21 \\
Virginia & 12,909 & 2.30 \\
\hline \hline
\end{tabular}

\subsection{HMDA}

The Home Mortgage Disclosure Act (HMDA), enacted by Congress in 1975 and implemented by the Federal Reserve Board's Regulation C, requires lending institutions to provide information about all applications for mortgage credit. Lenders must report an applicant's race, income, gender and occupancy status as well as the amount and lien status of the loan and the location of the property. The lender must then reveal the action taken, meaning whether the application was denied, approved, or withdrawn by the borrower.

\footnotetext{
${ }^{16}$ Using the database, it is also possible for us to generate the set of all possible offers and not just the best offer, which is the only one that appears in the search dataset.

${ }^{17}$ More precisely, a broker might do multiple searches for the same borrower on the same day, using different "scenarios" (for instance, a 15-year or a 30-year term). As we are only interested in the characteristics of borrowers who search, we would only keep one of these searches.
} 
HMDA's public-use data files are released on an annual basis and provide no information about application and action dates, but the confidential files to which we have access do include the date of the application as well as the date the loan was originated, if applicable. For our purposes, both dates are important. The application date tells us when borrowers took a costly step toward getting a new loan and the origination date allows us to link the application, which has only the minimal data demanded by HMDA, to loan-level data sets, which offer a wealth of additional information.

The HMDA data provide broad coverage of U.S. mortgage markets. According to Avery et al. (2010), about 8,400 institutions reported their applicant information in 2008, and the commercial banks, savings banks, and credit unions who reported to HMDA held more than 90 percent of the total mortgage dollars outstanding in their respective institutional categories.

\subsection{LPS}

The third dataset we use is a collection of records from large loan-servicing organizations that is maintained by Lender Processing Services, Inc. (LPS) 18 This dataset has fields for key variables set at the time of each loan's origination, including the amount of the loan, the value and location of the property that the secures the loan, whether the loan is classified as prime or subprime, and whether the loan is held in the lender's portfolio or has been packaged into a mortgage-backed security (MBS). We can also observe whether the loan is a first lien or a second lien as well as a host of interest-rate variables (such as whether the loan is fixed-rate or adjustable-rate and, in the latter case, the manner in which the interest rate changes).

As of September 2008, a few months before the LSAP program was announced, the LPS dataset covered nearly 60 percent of active residential mortgages in the United States, representing about 33 million loans with a total outstanding balance of nearly $\$ 6.5$ trillion. Avery et al. (2010) note that LPS coverage appears to overrepresent government-related lending and underrepresent jumbo and subprime lending.

For some of our analyses, we match LPS and HMDA data using a loan's origination date, the loan amount, and the property's zip code, allowing us to get detailed loan information for about 35 percent of the loans in HMDA. Other papers using this matching method or a similar process include Bubb and Kaufman (2009) and Elul (2009).

\footnotetext{
${ }^{18}$ Specifically, our data come from McDash Analytics, LLC, a wholly owned subsidiary of Lender Processing Services, Inc. Among housing researchers, the dataset is still generally called the "McDash data." The description of the LPS dataset in this section draws heavily from Cordell et al. (2008).
} 


\section{Findings}

In this section, we discuss the basic facts we uncovered about the effect of the LSAPs on mortgage markets. We divide our discussion into three parts, focusing first on how the available borrower opportunities changed with the LSAP announcement, then moving on to documenting changes in market activity and borrower composition.

\subsection{Changes to the Opportunity Set}

The complex way in which lenders price mortgages makes it a challenge to answer even the simplest question about how borrower opportunities changed after the announcement of the LSAP program. Most readers will not find it surprising that interest rates differ depending on things like product type, the lender, the size of the mortgage, and the borrower's credit history. But even when we hold all those things constant, a borrower who has narrowed down her choice to a specific mortgage product from a particular lender still faces a non-trivial decision. In this section, we first explain, as parsimoniously as possible, how to understand the borrower choice set. Then, we show how it changed with the announcement of the LSAP program on November 25, 2008.

\subsubsection{Understanding Borrower Choice}

Figure 1 shows an example of a "rate sheet," the main tool that a broker or loan officer uses to price a mortgage. Fifth Third Bank posted this particular rate sheet on June 7, 2010 but the format is fairly standard and rate sheets at the time of the announcement of the LSAPs looked similar.

To understand a rate sheet, focus first on the two columns in the upper left corner which show the contract interest rate and something called "discount points" respectively. The existence of these pairs of numbers has to do with the mathematics of bond pricing and reflects the difference between the par value of the loan, which is the amount the lender is financing, and the market value of the loan, which is the price paid by investors in the secondary mortgage market. If the contract interest rate is sufficiently high, then the market value will exceed the par value and vice versa if the interest rate is sufficiently low 19 To

\footnotetext{
${ }^{19}$ The secondary market trades asset-backed securities with certain coupon rates, formed by pools of loans with similar interest rates. Typically the underlying mortgages have an interest rate that is 50 basis points above the security's coupon rate (see, for example, www.mortgagenewsdaily.com/forums/t/24403.aspx). Investors in the agency MBS market are protected against default of the underlying mortgages (which is covered by the GSEs) but have to make predictions about future prepayments of the underlying mortgages due to refinancing or sales when valuing these MBS. These predictions, and thus the relative values of MBS with different coupon rates and of the underlying mortgages, are influenced by current and predicted future
} 
bridge the gap between market price and par value, lenders pay or receive the discount points on the loan at closing and thus, for a given loan, lenders will offer a choice of different contract interest rates and corresponding discount points 20 We define the borrower opportunity set as the set of combinations of available discount points and interest rates for a given mortgage transaction at a given time.

As an example, if the borrower agrees to pay an interest rate of 4.750 percent, the rate sheet shows "(1.575)" which means that the lender receives negative 1.575 percent of the loan balance (that is, the lender reimburses 1.575 percent of the loan balance to the borrower or his broker). The numbers in the two columns are for a base-case and the lower two-thirds of the sheet show all the adjustments for deviations from the base, typically in terms of additions to or subtractions from the number of discount points. For example, if the borrower wants an interest-only (IO) loan, then the lender reduces the number of discount points by three, so that a loan with a 4.750 interest rate will now involve a payment to the lender of 1.425 percent of the loan balance ( 1.575 points for the base case minus a 3 point adjustment). The broker or loan officer need not present the choice between an IO and a fully amortizing loan as different numbers of points for a given rate but may hold the points constant and offer different rates which, in this case, would roughly involve comparing a fully amortizing loan at 4.750 percent ( 1.575 points back at closing) versus an IO loan at 5.375 percent $(4.7-3=1.7$ points back at closing).

Discount points are not always visible to borrowers. If the number of discount points is negative from the borrower's perspective, the borrower or someone else (historically, an employer or sometimes, if it is a purchase mortgage, the property's seller) will pay them, or they will be folded into the balance of the loan. If the number is positive, meaning that the lender is paying money (often referred to as the "yield spread premium"), the broker or loan officer will not necessarily tell the borrower exactly how many points are coming in but may pocket the money or may pass the money on in the form of subsidized closing costs or even simply as cash paid at closing 21 Brokers typically use positive points to offer "no-points/no-close" (also called "no cost") mortgages, meaning that the borrower's closing costs are completely paid for through discount points 22

As a way of conveying complex information, rate sheets seem archaic, but are still the

interest rates, among other things.

${ }^{20}$ Discount points received by the borrower or the mortgage broker are usually referred to as "rebates" or "yield spread premium." We use the term "discount points" for both positive and negative points because there is no conceptual difference between the two.

${ }^{21}$ In a recent paper, Woodward and Hall (2010), using data from FHA loans in 2001, argue that many borrowers are confused and overpay for their broker's services. This seems particularly pronounced for borrowers who use a combination of discount points and cash to compensate their broker.

${ }^{22}$ Certain minor costs, such as per diem interest or transfer taxes, are excluded from this. For example, see http://www.mtgprofessor.com/A\%20-\%200ptions/no-cost_mortgages.htm for more detail. 
main method of disseminating loan prices. That said, electronic replacements have emerged in recent years and one of them, LoanSifter, provides the data for much of what follows in our analysis. LoanSifter essentially digitizes rate sheets for hundreds of lenders, puts the information in a relational database and sells access to brokers and loan officers and, in some cases, directly to potential borrowers. Rather than use the rate sheet and a calculator to figure out different rates and points, with LoanSifter a broker or loan officer can simply punch in the borrower's characteristics and the desired loan's characteristics and gets the relevant combinations of rates and points offered by dozens of lenders.

We now focus on the offers received by a prototypical borrower in California who wants a $\$ 300,000$ conforming mortgage. The property is worth $\$ 375,000$, so the loan's LTV ratio is 80 percent. The monthly payment is 35 percent of the borrower's fully documented income, the property is owner-occupied, and the borrower has a FICO score of 700. The loan is a 30-year fixed-rate mortgage without a prepayment penalty. The search specifies a 30-day lock meaning that the lender must fund the loan at the agreed price at any time in the next 30 days.

Figure 2 displays this borrower's opportunity set on two dates, one well before and one after the initial announcement of the LSAPs. Since we are looking from the borrower's perspective, we focus on the points received by the borrower for a given interest rate. In other words, when the rate sheet shows "(1.575)," meaning that the lender pays 1.575 points, figure 2 shows the borrower receiving +1.575 points. Since there is a fair amount of dispersion in the number of points offered for a given rate across lenders, we need to decide on a statistic to focus on for the purpose of comparing rates on different days. Figure2, for example, shows the maximum number of points offered for a given rate, an approach that makes sense if we assume that brokers always choose the offer with the most possible points. However, brokers do not view all offers equally and may choose one with lower points when more points are available. In conversations with us, brokers indicated that a key issue, especially in this period, was the speed with which the lender could process documents-brokers said that they were willing to choose lenders who offered fewer points on deals where time was of the essence. Furthermore, the LoanSifter data shows that some lenders consistently offer fewer points than the maximum over long periods of time, a viable strategy only if some brokers accept such offers, an observation which suggests that some brokers do value the lower offers. As an alternative to the maximum, we also measure the mean and median offers below.

To understand why it is important to look at the whole set, compare the menu in figure 2 with a popular measure of rates in the mortgage market: the Freddie Mac Primary Mortgage Market Survey (PMMS), which reports a single combination of rates and points on a given day. Freddie Mac acknowledges the difficulty this entails, writing that: "Many lenders offer their customers a menu of rate-point combinations." Their solution is to "ask that they 
provide their most popular combination for the survey."23 Figure 2 illustrates the problems with this approach. First, a change in the combination of rates and points need not imply any shift of the curve but may instead reflect a move along the curve. Second, even if we focus on shifts in the entire curve, the effect is not uniform. For a borrower with our assumed characteristics looking to receive two points at closing, opportunities slightly worsened between November 5 and December 5 (more on this below), while for a borrower not looking for any points, opportunities have improved. To take a real-world example, compare two borrowers, one who is looking for a "no-points/no-close" loan and the other who is willing to pay closing costs. To make the no-points/no-close loan, the broker needs a lender willing to pay discount points but the figure shows that the rates for loans in which lenders paid two points at closing slightly increased across the two days depicted in the figure. By contrast, for a borrower willing to pay his or her closing costs, opportunities have significantly improved with the lowest offered contract rate more than half a percentage point lower than what was available one month earlier.

While so far, we have focused entirely on variation for a particular borrower, variation across borrower and loan characteristics matters too. The bottom two-thirds of the rate sheet shown in figure 1 consists of subtractions and additions (mostly) to the number of points a borrower must pay conditional on any given contract interest rate. Such adjustments, as they are known, shift the whole borrower opportunity set up or down. For example, at the time the LSAP program was announced, lenders required a 1 point adjustment for a borrower with a FICO score of 670 relative to our baseline of 700 . Graphically, this means that one should subtract one point from the y-axis in figure 2, making the " +1 " point line for the 700 FICO borrower the "par" line for a 670 FICO borrower. Clearly, this matters a lot: the reduction in interest rates at par for a 670 FICO borrower is negligible; to get a significant reduction in rates, the 670 FICO borrower has to pay at least one discount point whereas the 700 FICO borrower can get a reduction without paying points. What is key here is that the slope of the opportunity set flattened between the two dates in the figure-had the curve simply shifted horizontally to the left, a 670 FICO borrower looking for a par loan or a 700 FICO borrower looking to receive points would also have seen their opportunities improve.

\subsubsection{Effect of the LSAP program}

Figure 3 shows the borrower opportunity set based on mean offers on the day immediately preceding the November 25 announcement and the day immediately after for our prototypical borrower. The curve on the far right shows the changes in interest rates as a function of the number of points the borrower receives and illustrates one of our main findings: there is

\footnotetext{
${ }^{23}$ http://www.freddiemac.com/pmms/abtpmms.htm.
} 
wide variation in the rate reductions induced by the LSAP program announcement. If the borrower takes the loan at par and thus gets no assistance with closing costs from the lender, then he or she can get a rate reduction of 40 basis points. Any assistance with closing costs comes at a cost and a borrower requirement of 1.5 points is enough to eliminate any rate gain from refinancing.

So the first fact from figure 3 is that heterogeneity in borrowers' willingness to pay points mattered. Why might such heterogeneity exist? First, the return to paying points depends on how long the borrower enjoys the benefits of lower rates, so if the borrower plans to move or refinance soon it may not make sense to refinance unless the lender covers the closing costs. Second, liquidity constrained borrowers may not have the resources to pay points, and folding those costs into the balance of the loan typically results in another fairly substantial adjustment.

Figure 3 also allows us to explore the effects of the LSAP announcement across different borrowers. As mentioned in the previous section, differences in borrower and loan characteristics usually result in adjustments to points and not direct changes in the rates, and thus move the curves up and down. For example, a borrower with a FICO score of 650 paid an extra 1.5 points for any loan, an effect which can be seen in the figure by comparing the right axis to the left axis. For the borrower with a 650 FICO score, a loan at par on the day after the announcement actually resulted in a higher rate than on the day before. To derive any significant benefit from the LSAP announcement, this borrower would have had to come up with an upfront payment including both discount points and the closing costs.

Thus, what figure 3 shows is that not all borrowers benefited equally from the announcement of the LSAP program. Borrowers who faced a lot of adjustments or were unwilling to pay for their refinance, whatever the reason, stood to gain the least, and we would expect few of them to refinance. But figure 3 also show that for some borrowers, the benefits were large and potentially explain the major response documented in the next section.

Our discussion has emphasized why looking at a single interest rate as an indicator of credit conditions in the mortgage market is both difficult and misleading. Nevertheless, for comparison with our findings, figure 4 shows several commonly used indexes of mortgage interest rates in the period immediately before and after the LSAP program was announced. The first salient fact is that the three indexes do not concur on the effect of the LSAP announcement, with the New York Times index (NYT) showing a fall before the announcement, the Wall Street Journal (WSJ) showing a fall right after, and the Freddie Mac index showing no change at all. Given the variation shown in figure 3, the lack of concordance across the indexes is not surprising. Further, as mentioned above, there is no way to know whether the number of points offered for a given rate rose, fell, or stayed the same nor can one find out whether or not one could get a lower rate by paying additional points. 
One question is whether the November 25 move was a typical day-to-day fluctuation in the opportunity set or whether it was in fact a significant shift. Figures 5 to 7 show that it was not typical but such shifts are not unprecedented either. Figure 5 shows that dayto-day fluctuations in the number of points offered for different interest rates traded in a narrow band in the days immediately preceding and immediately following the November 25 announcement of the LSAPs. But earlier in the sample, in the days immediately before and after the presidential election, we see even bigger shifts although these quickly offset each other.

What is significant about the moves associated with the LSAP announcement, in contrast to other movements in the sample, is that where the changes in early November seem to have shifted the entire curve, the LSAPs appear to have compressed the distribution of points for different rates. While for high rates (for instance, 6.5 or 7 percent), the number of points offered changed little, the number of points our prototypical borrower had to pay to get a relatively low rate (for instance, 5 or 5.5 percent) decreased substantially. To repeat an observation already made in the previous subsection, for a borrower who needed to receive points at closing, the LSAPs seems to have made little difference. For a borrower who was willing to pay points, rates went down in a way which was persistent and even improved over time. This decline can be seen in figure 6 which plots the borrower's opportunity set on all Fridays in our data. After November 25, the curves move to the left, meaning that lower rates are offered, but also shift downward somewhat, meaning that fewer lenders make offers where the borrower or his broker receive discount points. Figure 7 illustrates this rate movement directly by looking at the path of interest rates for two potential borrowers, one who expects to receive a point and the other who expects to pay a point 24 The improvement in rates is more marked for the borrower willing to pay than for the borrower expecting to receive money that could cover at least part of his or her closing costs. For instance, looking at median offers, the interest rate asked of the borrower willing to pay points decreases by more than 50 basis points from the week before the announcement to the week after the announcement, while for the other borrower the decrease is only about 25 basis points. Furthermore, by the end of our data period, the gap between the rates offered to these two borrowers widens further.

A final way to see the asymmetry of the interest rate changes associated with the LSAPs is to look at the number of offers made for different contracts. The opportunity sets differ across lenders and particular rates or points are available with some lenders and not others.

\footnotetext{
${ }^{24}$ These series are constructed by taking for each lender the offers that are closest to paying or requiring one discount point, and interpolating to get an estimate of the rate that this lender would charge. For instance, if a lender offers to pay 0.9 points for a loan with an interest rate of 5.375 percent and 1.05 points for a loan with an interest rate of 5.5 percent, our guess is that for a loan that pays 1 point the lender would charge an interest rate of 5.458 percent.
} 
As figure 8 shows, in the weeks after the LSAPs were first announced, the number of lenders willing to offer loans with positive points appears to decline dramatically. While immediately before and during the week after the November 25 announcement, practically all lenders who offered loans with one negative point also offered loans with one or more positive points, in early 2009 there were some weeks when fewer than 10 percent of these lenders offered a loan that paid one point.

\subsection{Changes in Activity}

The announcement of the LSAPs had a large and immediate effect on refinancing activity, and this effect persisted until around April 2009, with peaks in mid-December, early to midJanuary, and mid-March to mid-April. However, no similar effect can be detected for home purchase mortgages 25

Figure 9 displays the monthly volume of originations for purchase and non-purchase mortgages in the LPS dataset from 2006 to 2009. The figure shows that refinancing volumes in early 2009 reach levels higher than in 2006, and were much higher than in the second half of 200826 Origination volumes for home purchase mortgages, on the other hand, have exhibited a strong downward trend since 2006, and it does not seem that the LSAP program has done much to reverse this trend. Origination volumes for purchase mortgages also have a strong seasonal component, as home purchases tend to occur predominantly in the second and third quarters of the year. This further raises the difficulty of detecting whether the LSAPs had an effect on activity for purchase mortgages.

While the number of mortgage originations is what we ultimately care about, the shortcoming of the LPS data is that it does not contain any information about when the borrower applied for the mortgage, which makes it difficult to assess the "high frequency" effect the LSAPs had on activity. The private-use HMDA dataset overcomes this issue, as it contains application dates as well as outcomes (whether an application led to an origination, was denied or withdrawn, etc.) 27 Figure 10 shows that the volume of refinance mortgage applications increased substantially after November 25, 2008. While during the week of November 17 about 83,000 refinancing applications were made, this number more than doubles to 197,000 for the week of December 1 and then further increases to over 327,000 in the

\footnotetext{
${ }^{25}$ Throughout this and the next subsection, we focus on first-lien mortgages made to owner-occupiers of one-to-four-family dwellings (including condominiums). Conforming as well as government-insured (FHA) and government-guaranteed (RHS/VA) loans are included.

${ }^{26}$ The data also show that there was a relatively short-lived refinancing boom in early 2008.

${ }^{27}$ Other potential outcomes are: "Application approved but not accepted" which applies for instance if an application is approved but subject to conditions that the borrower is unable or unwilling to fulfill; "Incomplete"; "Preapproval request denied"; and "Preapproval request approved but not accepted."
} 
week of December 15.28 The two weeks around Christmas and New Year's are (unsurprisingly) more quiet, before the series reaches its peak of over 423,000 applications in the week of January 5. The volume then drops a little but increases again around March 18 (when the extension of the program is announced) and remains around 300,000 weekly applications for five weeks. Again, no similar effects can be detected for home purchase mortgages 29

The change in refinance application volume was indeed extraordinarily large. If we consider bi-weekly changes in log application volume, the standard deviation of this measure from January 2008 to November 23, 2008 was about $25 \mathrm{log}$ points. The surge in applications between the weeks of November 17 and December 1, on the other hand, was $87 \log$ points - an increase of about 3.5 standard deviations.

Another way to quantify the impact of the program and of important policy announcements is to look at the volume of mortgage quote searches in LoanSifter. These data also hint at the type of refinancing occurring - "rate and term" (refinancing of an existing mortgage in order to change the interest rate and/or term without raising the loan balance) or "cash-out" in which case additional cash above the balance of the existing liens is taken out. (HMDA does not distinguish between the two types; LPS does in principle, but a large proportion of the loans it tracks are in the "refinance (unknown cash)" category.)

Figure 11 shows that there was a large increase for rate-and-term searches, a smaller but still non-negligible increase for cash-out refinances, while the time series for purchase mortgages shows a slight uptick after the announcement but generally remains flat over the whole sample range. The volume of rate-and-term searches increased from about 5,100 during the week of November 17 to 18,800 two weeks later and to almost 31,000 for the week of December 15. The corresponding weekly numbers for cash-outs are 3,300, 6,500 and 8,200 , respectively. Thus, the number of cash-out searches increased by a factor of 2.5 after the initial announcement of the LSAPs, but due to the much larger increase in rate and term search volume, the proportion of cash-out searches fell from about 40 percent of all refinancing searches to below 25 percent in mid-December and throughout January.

The HMDA application and LoanSifter search volume data can also be used to get an idea of the very high frequency effects on activity of important policy announcements. We concentrate on November 25, 2008, the day the LSAPs were first announced (at 8:15 a.m. EST), and on March 18, 2009, when the program's extension was announced as part of the

\footnotetext{
${ }^{28}$ During the week in which the LSAP was announced, which contained Thanksgiving, about 112,000 applications were made. We look at daily application volume below.

${ }^{29}$ There is a third loan category in HMDA, "Home Improvement," which consists of loans "to be used, at least in part, for repairing, rehabilitating, remodeling, or improving a dwelling or the real property on which the dwelling is located" (http://www.ffiec.gov/hmda/glossary.htm). This category may include loans not secured by a dwelling, and for this reason and because this loan type only makes for about 4 percent of applications in our data, we do not include it in our analysis.
} 
regular FOMC statement (released around 2:15 p.m. EST). Table 2 shows large increases in refinance application volume (from the HMDA data) and LoanSifter search activity on the days of announcements and immediately afterwards. Note that the six-hour difference in the timing of the two announcements means that while large effects can be seen the day of the announcement in November, in March the largest effect occurs the day after the announcement (March 19). Compared to one week before the announcement, application volume is about 2.5 times larger on November 25 and about twice as high on March 19. The growth in search volume is even more pronounced.

Thus, the announcement of the program and its extension had very large and immediate effects on activity on the demand side. While this is an interesting and important fact by itself, it could be that this does not translate into a higher number of originations, if for instance the borrowers who rush in after the announcement have poor credit and subsequently are denied a mortgage. Table 2 shows that the opposite was the case. The percentage of refinance applications that turned into originated mortgages increased by more than 15 percentage points after the announcement on November 25, and the table's other columns show that this was in large part due to a decrease in the percentage of originations that were declined (and to a much smaller extent to withdrawal of earlier applications). This hints at a change in the composition of borrowers, which is further discussed in the next subsection.

Figure 12 shows that this increase in the percentage of applications that led to originations was not a short-lived phenomenon, but rather appears to have been subject to a discrete increase in November 2008 after it had been in decline throughout 2008 30 Importantly, this means that simply looking at the number of applications, as for instance captured by the index of the Mortgage Bankers Association, would lead one to underestimate the true extent of the LSAP program's effect on refinancing activity.

Finally, the HMDA data can also shed light on the processing time required by lenders after the application volume exploded. Anecdotal evidence from market participants suggests that lenders had a hard time handling the increased volume, which may have prevented them from lowering rates more than they did. Figure 13 shows that the median number of days between application and origination indeed increased substantially after November 2008, from less than 30 days between January to November 2008 to over 40 days in January 2009 and almost 50 days in April and May 2009. This could be due to lenders taking longer to process applications, or alternatively to borrowers waiting longer before locking their rate because they wanted to exploit potentially better offers. The latter factor would not explain, however, why the time between application and action also goes up for applications that get

\footnotetext{
${ }^{30}$ The figure also shows that for home purchase mortgages, there also appears to have been an increase, though of much smaller magnitude.
} 
denied, as the figure shows. Thus, our evidence is consistent with the idea that lenders were somewhat caught off-guard by the surge in the number of applications.

\subsection{Changes in the Composition of Borrowers}

We now turn our attention to changes in the distribution of borrowers who refinanced before and after the announcement of the LSAPs, and in particular on the distribution of FICO scores among borrowers who searched for and obtained a mortgage in the relevant period 31 We also confirm our findings by looking at changes in the distribution of applicants' income in the HMDA data. Data on applicants' income may be easier to interpret than FICO scores, and unlike FICO scores, are also available for applicants who are denied a mortgage 32

We start by looking at the longer-term trends in borrower FICO scores of originated mortgages. Figure 14 shows that in the LPS data there had been a slight upward trend in median (as well as the top and bottom quartile) borrower FICO scores for originated refinance and (to a smaller extent) purchase mortgages between 2006 and the end of 2009 . What is also evident from the graph's left panel is that for refinance mortgages there were two large increases in early 2008 and early 2009, coinciding with the surge in originations discussed earlier.

In figure 15] we use LPS data merged with HMDA data from January 2008 to October 2009 to get the application date of originated loans. This figure shows that the increase in borrower FICO scores for originated loans occurs right around November 25. In particular, the bottom 25th percentile of FICO scores, which fluctuated around 675 for application dates between August and mid-November 2008, jumps to 725 and stays around that value until about May 2009, at which point it slightly decreases to around 700. The median and top quartile FICO also witness a significant but slightly less dramatic increase around November 25. An alternative way to quantify the significant changes in the bottom of the FICO distribution is to consider the share of refinance originations made to borrowers with a FICO score below 720 (which is supposed to approximate the median credit score in the U.S. population). This share fluctuates around 30 to 35 percent for most of 2008 but then drops to around 20 percent for application dates between November 25 and April 2009, before increasing again to between 25 and 30 percent in the summer of 2009.

\footnotetext{
${ }^{31}$ The FICO score, which ranges from 300 to 850, is supposed to capture a person's creditworthiness and the likelihood of debt repayment. www.myfico.com/CreditEducation/CreditScores.aspx reports that the national distribution of scores is left-skewed, with 27 percent of the population having a score below 650,15 percent between 650 and 699, 18 percent between 700 and 749, and 40 percent are above 750. The median score is often reported to be around 720. It is not clear what time period these numbers are from and whether the distribution was affected by the recent recession.

${ }^{32}$ The income reported in HMDA is "the total gross annual income an institution relied upon in making the credit decision" (www.ffiec.gov/hmda/glossary.htm).
} 
Table 3 provides a high-frequency view of the changes in the FICO composition of borrowers around November 25. We consider five different FICO score categories and construct an index with the number of applications leading to originated refinancing mortgages for 10 business days, with the number on the day before the announcement set to 100 . The table shows that for all FICO categories, there was a large increase in successful applications on November 25 and the next few business days, but the magnitude of the increase differs widely across FICO categories. Applications for borrowers with FICO scores below 700 increase by about 150 percent (which is the average across the five business days after the announcement shown in the table), while for borrowers with FICO scores above 760 the increase is about 600 percent. In between these two extremes, the magnitude of the effect increases monotonically in FICO scores.

Other underwriting criteria for originated mortgages show a similar pattern of increasing credit quality, although the effects are not nearly as stark as they are for FICO scores. Specifically, the distribution of loan sizes shifts upward, and loan-to-value ratios and payment-toincome ratios shift downward in the immediate aftermath of the LSAP announcement. In addition to smaller overall magnitudes, another difference is that while the FICO score effects are quite persistent, the effects on loan amount, for example, while initially strong, dissipate fairly quickly and by the start of 2009 only show a relatively small change.

The discussion so far has focused on the characteristics of borrowers who obtained a mortgage before and after the announcement of the LSAPs. However, the HMDA data allows us to look another important characteristic, applicant income, for both successful and unsuccessful applicants 33 As figure 16 shows, the median income on applications for refinance mortgages increased from about $\$ 65,000$ the week before to just under $\$ 80,000$ the week of the LSAP announcement, and to about \$85,000 in December 2008 and January 2009. This mirrors the changes in the distribution of borrower FICO scores discussed above.

HMDA also allows us to address the question of whether the compositional shift in originations resulted from increased denials of low-income borrowers. Figure 17 shows that this does not seem to be the case, as denial rates fell for all income groups by roughly the same amount. This implies that, at least for income levels, denials did not drive the changes in the borrower composition of originated mortgages.

The above analysis strongly suggests that the distribution of borrowers that obtained refinance mortgages was directly affected by the announcement of the LSAP program. There is more than one potential explanation for this shift, and we will discuss the different possibilities in more detail in section 6. The search data from LoanSifter provides suggestive evidence of one particular channel, namely that highly creditworthy borrowers (with high

\footnotetext{
${ }^{33}$ Meanwhile, HMDA does not collect FICO scores or loan-to-value ratios, so we do not have this information for rejected applications.
} 
FICO scores and income) are more financially sophisticated and pay closer attention to financial market developments that may affect available mortgage rates. Figure 18 shows that the FICO score distribution of searches in LoanSifter indeed moved upwards somewhat after November 25, 2008. However, this increase is less dramatic than for originated mortgages. For instance, the median FICO score for rate-and-term refinance searches, which was at 740 throughout October and November 2008, reached 750 by early December and more or less stayed there until April. For cash-out searches, which as we saw earlier represent a smaller percentage of the total search volume, the shift was slightly more pronounced, but still quite a bit smaller than the one for originated mortgages. This suggests that, apart from a lack of borrower interest, other factors may have contributed to the relatively weaker increase in refinancing volume for borrowers with low FICO scores.

\section{The Economic Effects of the LSAP Program}

As explained in section 2, policymakers instituted the LSAP program both as a way of stabilizing housing markets and as part of a broader macroecononomic stimulus. In the previous section, we documented changes in the primary mortgage market associated with the program's announcement and implementation. In this section, we discuss some deeper, more speculative questions about how the LSAPs affected the U.S. economy.

On the question of macroeconomic stimulus, our research can shed some light on whether the LSAPs stimulated consumption by reducing mortgage payments and freeing up cash flow. The argument, as discussed in section 2, is that a large share of the reduction in monthly mortgage payments facilitated by the LSAP program would show up in consumption. However, economic science remains undecided about how big that share should be. As Canner et al. (2002) write:

the amount of incremental spending - that is, the amount above that which would have occurred in the absence of refinancing - is unclear.

But theory combined with the received wisdom of 50 years of analyzing household consumption patterns provide some insights - although the effects of rate-and-term refinancing have not generated much interest in the literature, in contrast to the attention paid by some studies to cash-out refinancing 34

We can start with the canonical frictionless permanent income model in which households can borrow unlimited amounts at the riskless rate and know their current wealth and future income with certainty. In this case, the effects on consumption are likely to be small. First, as Canner et al. (2002) point out, any reduction in monthly mortgage payments by a

\footnotetext{
${ }^{34}$ See Cooper (2010) for a recent example.
} 
borrower is offset by reductions in income to investors, and the assumption of a frictionless economy implies that the two groups' marginal propensities to consume are the same. The fact that many U.S. mortgage-backed securities are held by foreigners might mitigate this effect by generating reductions in consumption overseas and gains at home, although in a truly frictionless world the reduction in demand in the rest of the world would affect the U.S. economy. Second, the reduction in the present value of promised mortgage payments depends on the borrower's expected length of tenure in the current property. Recent research by Ferreira et al. (2009) shows a two-year sale hazard of 14 percent, although the authors argue that the hazard is likely lower now due to the prevalence of negative equity among homeowners 35

Researchers have argued that the frictionless model discussed above yields an unrealistically low marginal propensity to consume out of current cash flow, for instance due to the model's idealized treatment of borrowing. Critics argue that models in which households cannot borrow (or only at a rate much above the riskless rate) generate marginal propensities to consume more in line with the data. Arguably, the popular media account quoted in section 2 assumes that the household receiving the payment reduction faces a binding borrowing constraint.

Higher marginal propensities to consume would amplify the effects of the LSAP program. First, one can argue, as do Canner et al. (2002), that borrowers' marginal propensity to consume should be much higher than that of investors, invalidating the argument that their respective marginal-consumption effects cancel each other out. Moreover, the models predict that some highly constrained households would have marginal propensities to consume close to or even equal to one, meaning that any reduction in monthly payments would translate into a one-for-one increase in consumer spending.

The problem with appealing to high MPCs in measuring the benefits of the LSAP program is that the data discussed in section 4.3 suggests that the borrowers who refinanced following the LSAP program's announcement were the ones least likely to be credit-constrained. Recall that we showed that the response was heavily skewed toward borrowers with very high credit scores - with a six-fold increase in refinancing for borrowers with FICO scores above 760 compared with a doubling for those with FICO scores under 700. Borrowers with high FICO scores have less debt to begin with, as that is one of the scoring criteria, are viewed by lenders as more creditworthy, and thus have excellent access to credit even without a

\footnotetext{
${ }^{35}$ Of course, having little or no positive equity also makes it more difficult or expensive to refinance in the first place. The U.S. Treasury designed the Home Affordable Refinance Program explicitly to allow borrowers with negative equity to refinance but the program has not had a major impact. According to the Federal Housing Finance Agency (FHFA), "In 2009, Fannie Mae and Freddie Mac purchased or guaranteed more than 4 million refinanced mortgages. Of this total, 190,180 were HARP refinances with LTVs between 80 percent and 125 percent" (see http://www.fhfa.gov/webfiles/15466/HARPEXTENDED3110\%5B1\%5D.pdf).
} 
reduction in monthly mortgage payments.

On the issue of house prices, the evidence appears inconclusive. First, some researchers have argued that there is little support in the data for a close link between interest rates and house prices. Campbell et al. (2009) looked at the price-rent ratio and argued that:

Our finding that the expected net present value of the risk premium for housing and the risk-free rate of interest are negatively correlated implies that the link between the level of house prices and real interest rates is more complex than [recent] interpretations of history suggest. Indeed, our results provide evidence that changes in risk-free interest rates may not have done much to change housing valuations over the 1975-2007 period. (p. 91)

One might also imagine that the opportunity to exploit the historically low mortgage rates could have had an effect on purchase activity above and beyond the traditional channels. However, there is little evidence to support this idea. Figures 10 and 12 show that the LSAP program appears to have had little effect on applications or originations for purchase mortgages, with the increase over the next few months largely reflecting seasonal patterns in housing. This is not surprising since the number of mortgage applications and originations is tied to the number of actual purchases and other data sources already confirm that the LSAPs did not lead to an increase in purchase transactions.

One could counter that if the demand curve shifted out but the supply of properties was inelastic, then the LSAPs may have increased demand without a corresponding increase in transaction quantities. We have two places in the data where we might detect such a "hidden" increase in demand. The first is in search activity. Figure 11 shows that there was an increase in search activity for purchase mortgages right after the LSAP program announcement, but that it was far smaller than the increase in search activity for refinance mortgages. Furthermore, it is difficult to determine whether this simply reflects a seasonal change or whether it really reflects an increase in demand triggered by lower financing costs.

The second place to look for evidence that the LSAPs increased the demand for houses would be in the composition of loans. An obvious thing to look at is whether the loan amounts in searches or applications increased after the announcement of the LSAPs, but we find that this is not the case. Another potential argument for the value of the LSAP program is that lower nominal mortgage rates in combination with lender limits on the payment-to-income ratio increase the amount a borrower can spend conditional on a given level of income. Since this effect only matters for credit-constrained borrowers, an increase in the number of borrowers likely to be constrained would furnish evidence that the LSAP program had an effect. But unlike the evidence with the refinance mortgages, no change in the characteristics of purchase mortgages accompanied the announcement of the LSAP program. 
We caution the reader that the lack of evidence in favor of a hypothesis does not constitute evidence against it, so whether the LSAP program affected house prices remains to be determined.

\section{Open Questions}

Our finding that the FICO-score distribution of successful refinance applicants changed so drastically with the announcement of the LSAPs is somewhat surprising and, we believe, deserves further investigation. Different hypotheses may - individually or jointly - be able to explain why relatively fewer borrowers with low FICO scores refinanced after the program announcement.

Possibility 1: The potential benefits of refinancing were smaller for borrowers with low FICO scores, due the change in the slope of the borrower opportunity set coupled with price adjustments required by the GSEs. As we showed in section 4.1, adjustments to the loan price, due to certain characteristics of the borrower or of the loan, can interact with a shift in the opportunity set to amplify or mute the overall effect on rates. When the slope of the opportunity set is steep, such adjustments matter relatively little for the rate, because it is "cheap" to offset them through a higher rate. But if the opportunity set is flat, they matter a lot. In the case of the LSAP program, which both shifted and flattened the opportunity set, mortgage rates decreased significantly less for borrowers facing large adjustments than for borrowers not subject to adjustments.

Interestingly, the existence of price adjustments tied to the creditworthiness of borrowers is a relatively new phenomenon in the agency loan market (in contrast to the subprime market, where such adjustments played a central role). Fannie Mae announced its "LoanLevel Price Adjustments" (LLPAs) on November 6, 2007, a little more than a year before the announcement of the LSAPs. Fannie Mae attributed the move to "unprecedented changes in the market, including declines in national home prices that are expected to continue through the end of 2008," and said that it would "ensure that [its] pricing is appropriate."36] Freddie Mac followed suit a week later with a set of virtually identical measures referred to as "Postsettlement Delivery Fees."

The main determinants of the LLPA that is added to the price of a loan are the loanto-value ratio (LTV) and the borrower's FICO score. Table 4 shows the evolution of Fannie Mae's LLPAs for different FICO-score categories for a non-cash-out loan with an LTV between 75 and 80 percent 37 When the LSAPs were announced, borrowers with a FICO score

\footnotetext{
${ }^{36}$ https://www.efanniemae.com/sf/guides/ssg/annltrs/pdf/2007/0716.pdf.

${ }^{37}$ The evolution of Freddie Mac's Postsettlement Delivery Fees was virtually identical and can be traced at http://www.freddiemac.com/sell/guide/bulletins/archive.html.
} 
below 680 had to pay at least 1.75 points or more on such a loan than borrowers with a FICO score above 740,38 Figure 5 gives a good indication of the rate differential that an adjustment of 1.75 points would have induced. For instance, the top panel of the figure shows that in October a vertical shift of 1.75 points corresponded to a rate differential between 75 and 100 basis points in the region around par (that is, 0 points). In the aftermath of the announcement, however, the narrowing of the gaps between the lines means that the rate differential increased to about 150 basis points. As a consequence, the relative incentive to refinance increased much less for borrowers with low FICO scores than for borrowers with high FICO scores - at least if the former had an LTV sufficiently high to trigger a LLPA.

Figure 19 provides evidence that the LLPAs indeed seem to have affected refinancing behavior during the first half of 2009, our main period of interest. The figure shows the number of conventional refinance mortgages by FICO score value originated in the period of January to July 2009, and also (for comparison) during the first three months of 2008 (when refinancing activity was also somewhat elevated, as discussed earlier). There are strikingly large changes in origination volume right around the cutoffs where the LLPAs increase - at FICO scores of 680,700 , and 720 . In all three cases, the number of loan originations is more than 25 percent higher right above the FICO cutoff than it is right below. Interestingly, in 2008 , such a large jump is only observed at the FICO score value of 680 , above which at the time no LLPAs were charged 39 Of course, these jumps should not directly be interpreted as the "treatment effect" of LLPAs on individual borrowers' refinancing, because a borrower with a FICO score of 697 (say) can make sure his score goes above 700 by paying off some other debt and waiting a few weeks 40 However, even in that case, the LLPAs represent a friction in the refinancing process that generates some deadweight loss for borrowers.

Possibility 2: Borrowers with low FICO scores may, on average, be less able or willing to pay their closing costs when refinancing. There are several reasons why this might be the case. One possibility is that low-FICO borrowers are liquidity constrained and as a consequence have a high "effective discount rate," meaning that they value having money today much

\footnotetext{
${ }^{38}$ At the end of December 2008, Fannie Mae announced that LLPAs for such borrowers would increase by another 0.75 points for loans delivered to Fannie Mae on or after April 1, 2009. Our LoanSifter queries show that new LLPAs are added to ratesheets about two months before they become effective for delivery, so that in this case the points required by lenders from borrowers with relatively low FICO scores increased around the end of January.

${ }^{39}$ There are smaller, local jumps in the 2008 data at FICO scores of 700 and 720 . As there were no LLPAs for these FICO scores at the time, it is not clear why borrowers above these cutoffs would be more likely to refinance. One possibility is that lenders idiosyncratically added surcharges, for instance in order to improve the average quality of their loan pools.

${ }^{40}$ As can be seen in the figure, this kind of behavior may have been prevalent in 2008. However, in the 2009 data, the jumps at the cutoff points persist throughout a given FICO score category.
} 
more than having money tomorrow (from saving on mortgage payments). Another possibility is that such borrowers expect to move or to refinance again relatively soon, so that they would rather pay a higher interest rate during the short period that they expect to keep the mortgage than pay the closing costs. Borrowers who want the lender to pay for their closing costs require positive discount points and, as we discussed in section 4.1, rates available to such borrowers did not decrease as much as rates for borrowers willing to pay points 41 As a consequence, such borrowers may be less likely to refinance.

This possibility is of course related to the first possibility discussed above, as both have to do with the flattening of the opportunity set, but this would apply even in the absence of LLPAs. Given the importance of the slope of the borrower opportunity set in determining which borrowers will be willing or able to refinance, it is important to understand how it is determined. The slope of the borrower opportunity set depends on the prices for MBS with different coupon rates: the larger the price differential between high-coupon and low-coupon MBS, the more points lenders are willing to pay in exchange for a higher rate. Figure 20 shows that this price differential shrank significantly around the date of the LSAP program's initial announcement and stayed relatively narrow compared to June through November 2008 (a period that in terms of price differences is also relatively representative of earlier data since 2002). Further, MBS prices did not increase nearly as much for high-coupon MBS as for low-coupon ones. The price differential is of course influenced by the overall yield curve in the economy, which summarizes expectations about the paths of future interest rates, which in turn matter for projected prepayments and thus MBS valuation. During the particular episode we focus on, the fact that the Fed predominately purchased low-coupon mortgages (see Gagnon et al. 2010) may also have contributed to the price compression.

Possibility 3: Borrowers with low FICO scores are less likely to be able to obtain a new mortgage. Given the evidence presented earlier, this seems somewhat unlikely. We saw in the HMDA data that the percentage of applications that were denied fell very significantly after November 25, 2008 and that this decline seems to have occurred as much for low-income borrowers as for high-income borrowers. However, it is still possible that borrowers with poor credit were "rationed out" of the market by brokers, such that they would never even have filed an application (and thus would not show up in the HMDA data). Indeed, there is some anecdotal evidence from brokers that supports this story. They say that borrowers with good credit were given priority because of the lower chances of an application being denied for such borrowers. This may have been important because, as we saw earlier, brokers

\footnotetext{
${ }^{41} \mathrm{An}$ alternative way to finance closing costs would be to fold them into the loan balance. However, this seems to be done relatively infrequently, mostly due to the fact that this would increase the loan's LTV ratio and thus may push the LTV over a threshold where LLPAs increase, or qualify the mortgage as a cash-out, which also requires higher LLPAs.
} 
and lenders faced capacity limits; thus the logical thing for them to have done would be to focus on the "easiest" loans.

Possibility 4: Borrowers with low FICO scores are more likely to have little or no equity in their home, such that refinancing may not be possible or cost-efficient for them. Being "underwater" (that is, having a mortgage balance that exceeds the home's current appraisal value) is not the only condition that can prevent refinancing. LLPAs (which increase in the LTV) and private mortgage insurance (which is required if theLTV exceeds 80 percent) would significantly increase the cost of a refinance mortgage. These factors may have important effects on refinancing behavior (see Caplin et al. 1997) and in ongoing research we will try to proxy for them by looking at geographic areas that have witnessed different price paths.

Possibility 5: Borrowers with low FICO scores may not pay as much attention to rate changes as do more financially sophisticated (high-FICO) borrowers and thus the former may fail to refinance despite low rates. It is very possible that many borrowers fail to refinance even though it is optimal for them to do so, and previous work (for example, Campbell 2006) has found that this mistake seems more prevalent among borrowers with characteristics that correlate with low FICO scores. Indeed, such borrowers are sometimes called "woodheads" in the mortgage industry (Deng and Quigley 2006), precisely because they are slower to refinance. As discussed earlier, the LoanSifter search data provides suggestive evidence in support of this channel, but the change in the FICO distribution for searches is smaller than the change for originations, suggesting that differences in attention or sophistication are unlikely to explain the entire shift in borrower characteristics.

The above possibilities are of course not mutually exclusive, and it is also possible that additional factors played a role. In any event, investigating the contribution of these different channels to the shift in borrower characteristics after the announcement of the LSAP program remains a subject of ongoing research. A better understanding of this issue could improve the effectiveness of mortgage market interventions, especially if the goals include facilitating refinances for borrowers with poor credit. 


\section{References}

Avery, Robert B., Neil Bhutta, Kenneth P. Brevoort, Glenn B. Canner, and Christa N. Gibbs. 2010. "The 2008 HMDA Data: the Mortgage Market During a Turbulent Year." Federal Reserve Bulletin 96(April): A169-A211.

Available at http://www.federalreserve.gov/pubs/bulletin/2010/articles/HMDA/.

Bubb, Ryan and Alex Kaufman. 2009. "Securitization and Moral Hazard: Evidence from a Lender Cutoff Rule." Public Policy Discussion Paper 09-5, Federal Reserve Bank of Boston.

Available at http://www.bos.frb.org/economic/ppdp/2009/ppdp0905.htm.

Campbell, John Y. 2006. "Household Finance." The Journal of Finance 61(4): 1553-1604.

Campbell, Sean D., Morris A. Davis, Joshua Gallin, and Robert F. Martin. 2009. "What Moves Housing Markets: A Variance Decomposition of the Rent-Price Ratio." Journal of Urban Economics 66(2): 90-102.

Canner, Glenn, Karen Dynan, and Wayne Passmore. 2002. "Mortgage Refinancing in 2001 and Early 2002." Federal Reserve Bulletin 88(December): 469-481.

Available at http://www.federalreserve.gov/pubs/Bulletin/2002/1202lead.pdf.

Caplin, Andrew, Charles Freeman, and Joseph Tracy. 1997. "Collateral Damage: Refinancing Constraints and Regional Recessions." Journal of Money, Credit ES Banking 29(4): 496516.

Cooper, Daniel H. 2010. "Did Easy Credit Lead to Overspending? Home Equity Borrowing and Household Behavior in the Early 2000s." Public Policy Discussion Paper 09-7, Federal Reserve Bank of Boston.

Available at http://www.bos.frb.org/economic/ppdp/2009/ppdp0907.htm.

Cordell, Larry, Mark Watson, and James Thomson. 2008. "McDash Data Warehouse Seminar."

Deng, Yongheng and John M. Quigley. 2006. "Woodhead Behavior and the Pricing of Residential Mortgages." Working Paper Series 1015, Berkeley Program on Housing and Urban Policy.

Available at http://ideas.repec.org/p/cdl/bphupl/1015.html.

Duygan-Bump, Burcu, Patrick M. Parkinson, Eric S. Rosengren, Gustavi A. Suarez, and Paul S. Willen. 2010. "How Effective Were the Federal Reserve Emergency Liquidity Facilities? Evidence from the Asset-Backed Commercial Paper Money Market Mutual 
Fund Liquidity Facility." QAU Working Paper QAU10-3, Federal Reserve Bank of Boston. Available at http://www.bos.frb.org/bankinfo/qau/wp/2010/qau1003.htm.

Elul, Ronel. 2009. "Securitization and Mortgage Default: Reputation vs. Adverse Selection." Working Papers 09-21, Federal Reserve Bank of Philadelphia.

Available at http://ideas.repec.org/p/fip/fedpwp/09-21.html.

Ferreira, Ferreira, Joseph Gyourko, and Joseph Tracy. 2009. "Housing Busts and Household Mobility." Journal of Urban Economics 68(1): 34-45.

Gagnon, Joseph, Matthew Raskin, Julie Remache, and Brian Sack. 2010. "Large-Scale Asset Purchases by the Federal Reserve: Did They Work?" Staff Report 441, Federal Reserve Bank of New York.

Available at http://www.newyorkfed.org/research/staff_reports/sr441.html.

Hubbard, R. Glenn and Christopher J. Mayer. 2009. "The Mortgage Market Meltdown and House Prices." The B. E. Journal of Economic Analysis 6 Policy 9(3): 2223. Available at http://www . bepress .com/bejeap/vol9/iss3/art8/.

Stroebel, Johannes C. and John B. Taylor. 2009. "Estimated Impact of the Fed's MortgageBacked Securities Purchase Program." Working Paper No. 15626. Cambridge, MA: National Bureau of Economic Research.

Taylor, John B. and John C. Williams. 2009. "A Black Swan in the Money Market." American Economic Journal: Macroeconomics 1(1): 58-83.

Woodward, Susan E. and Robert E. Hall. 2010. "Diagnosing Consumer Confusion and Sub-Optimal Shopping Effort: Theory and Mortgage-Market Evidence." Working Paper No. 16007. Cambridge, MA: National Bureau of Economic Research. 
Table 1: Key Events in the Relevant Period

\begin{tabular}{ll}
\hline \hline Date & \multicolumn{1}{c}{ Event } \\
\hline \multirow{2}{*}{ November 25, 2008 } & $\begin{array}{l}\text { Initial LSAP announcement in which the Federal Reserve stated it } \\
\text { would purchase up to } \$ 100 \text { billion in agency debt, and up to } \$ 500 \\
\text { billion in agency MBS. }\end{array}$
\end{tabular}

Chairman Bernanke's speech, in which he stated that in order to influ-

December 1, 2008 ence financial conditions, the Federal Reserve "could purchase longerterm Treasury securities in substantial quantities."

Labor Department reports that nonfarm payroll employment fell by December 5, $2008 \quad 533,000$ jobs, the worst showing since 1974 and far more than the $e_{-}^{a}$ 350,000 that economists expected.

December 16, 2008

FOMC Statement: "The Committee is also evaluating the potential benefits of purchasing longer-term Treasury securities."

The Federal Reserve Bank of New York issues details of the LSAP

December 30, 2008 program and announces that "purchases are expected to begin in early January, 2009."

January 5, 2009 The New York Fed makes its initial purchase of agency MBS.

FOMC Statement: "The Committee also is prepared to purchase

January 28, 2009 longer-term Treasury securities if evolving circumstances indicate that such transactions would be particularly effective in improving conditions in private credit markets."

FOMC Statement: "To provide greater support to mortgage lending and housing markets, the Committee decided today to increase the size of the Federal Reserves balance sheet further by purchasing up to an additional $\$ 750$ billion of agency mortgage-backed securities, bringing March 18, $2009 \quad$ its total purchases of these securities to up to $\$ 1.25$ trillion this year, and to increase its purchases of agency debt this year by up to $\$ 100$ billion to a total of up to $\$ 200$ billion. Moreover, to help improve conditions in private credit markets, the Committee decided to purchase up to $\$ 300$ billion of longer-term Treasury securities over the next six months."

\footnotetext{
a"Ahead of the Tape," The Wall Street Journal, December 5, 2008 and "Job Losses Worst Since '74: 533,000 Shed in November" December 6, 2008, The Wall Street Journal.
} 
Table 2: Changes in Daily Application and Search Activity Before and After the Two Main LSAP Announcements

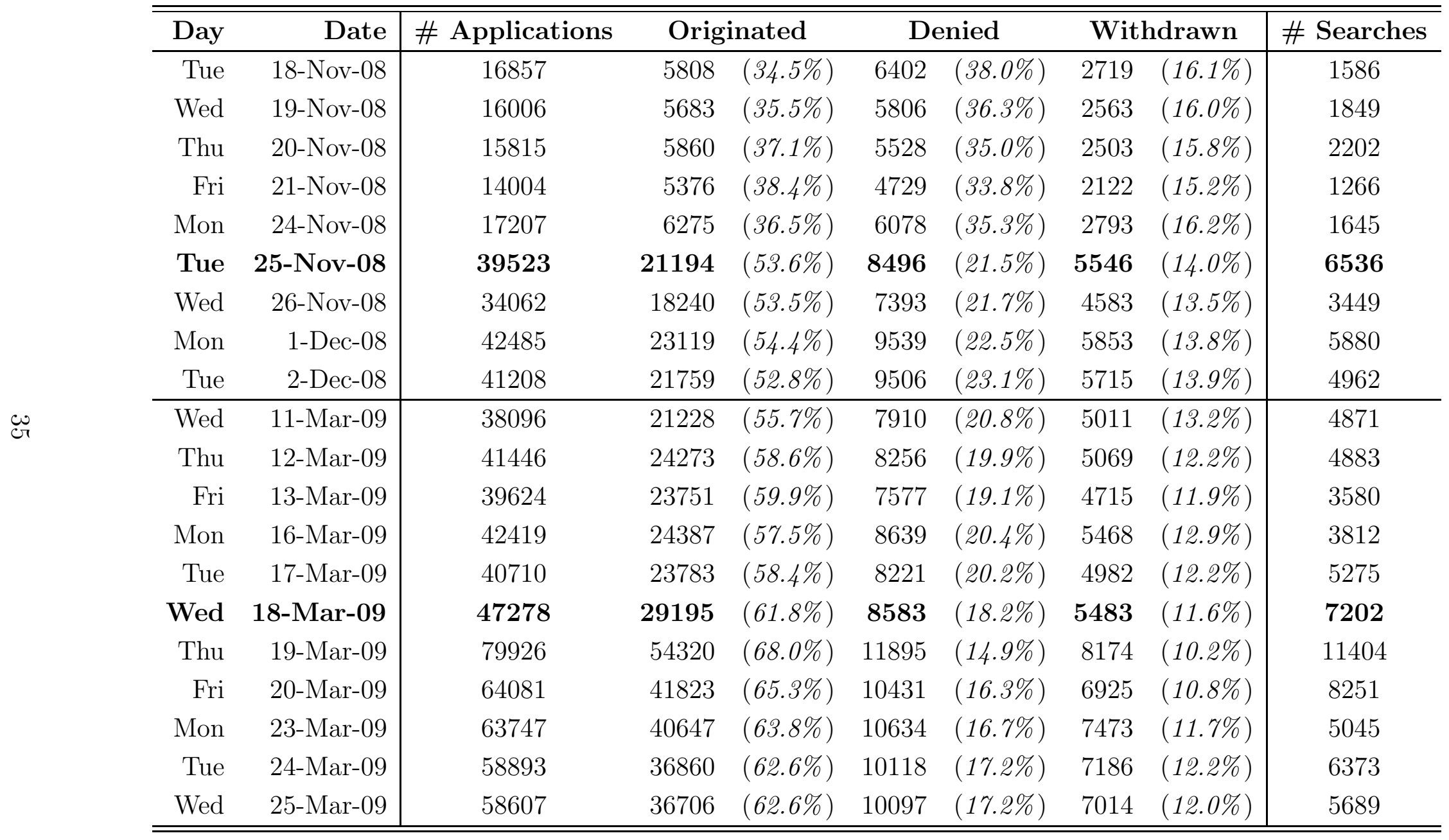

Sources: HMDA, LoanSifter, and authors' calculations.

Note: Weekends and Thanksgiving Thursday and Friday (November 27-28, 2008) are not shown. 
Table 3: Number of Loans Originated by FICO Score and Application Date

\begin{tabular}{lc|c|ccccc}
\hline \hline Month & Day & Total & $<\mathbf{7 0 0}$ & $\mathbf{7 0 0 - 7 2 0}$ & $\mathbf{7 2 0 - 7 4 0}$ & $\mathbf{7 4 0 - 7 6 0}$ & $>\mathbf{7 6 0}$ \\
& & $\#$ & \multicolumn{5}{|c}{$11 / 24 / 08=100$} \\
\hline \multirow{6}{*}{ November } & 18 & 693 & 93 & 114 & 72 & 81 & 63 \\
& 19 & 671 & 81 & 88 & 68 & 68 & 64 \\
& 20 & 724 & 97 & 84 & 53 & 73 & 76 \\
& 21 & 668 & 93 & 81 & 62 & 76 & 67 \\
& 25 & 897 & 100 & 100 & 100 & 100 & 100 \\
& 26 & 4636 & 245 & 365 & 383 & 476 & 604 \\
\multirow{4}{*}{ December } & 1 & 4789 & 226 & 382 & 454 & 532 & 747 \\
\hline \hline
\end{tabular}

Source: LPS, HMDA, and authors' calculations.

Note: Sample limited to loans with matched origination information from LPS and application date from HMDA. Weekends and Thanksgiving Thursday and Friday (November 27-28, 2008) are not shown.

Table 4: Evolution of Loan-Level Price Adjustments for Loans with a Loan-to-Value Ratio Between 75 and 80 Percent

\begin{tabular}{|c|c|c|c|c|c|}
\hline \multicolumn{2}{|c|}{ " Announcement Number } & $07-16$ & $08-04$ & $08-18 \mathrm{R}$ & $08-38$ \\
\hline \multicolumn{2}{|c|}{ Date Announced } & November 6, 2007 & March 6, 2008 & August 11, 2008 & December 29, 2008 \\
\hline \multicolumn{2}{|c|}{ Date Effective } & March 1, 2008 & June 1, 2008 & November 1, 2008 & April 1, 2009 \\
\hline \multirow{8}{*}{$\begin{array}{l}\text { FICO } \\
\text { score }\end{array}$} & $>=740$ & 0 & 0 & 0 & 0 \\
\hline & $720-739$ & 0 & 0 & 0.25 & 0.25 \\
\hline & $700-719$ & 0 & 0.5 & 0.75 & 0.75 \\
\hline & $680-699$ & 0 & 0.5 & 1 & 1.5 \\
\hline & $660-679$ & 0.75 & 1.25 & 1.75 & 2.5 \\
\hline & $640-659$ & 1.25 & 1.75 & 2.25 & 3 \\
\hline & $620-639$ & 1.75 & 2.5 & 2.75 & 3 \\
\hline & $<620$ & 2 & 2.75 & 2.75 & 3 \\
\hline
\end{tabular}

Source: https://www.efanniemae.com/sf/guides/ssg/2010annlenltr.jsp 
Figure 1: An Example of a Rate Sheet

Visit our wobsite at wwe.53.com/wholesalemortgage E-mail: WholesaleRegistation.Cincinnat@53.con To Register and Lock Rates Online:

Go to unw. 53. com/wholesalemortgage and select "Wholesale Connect". Contact Your $5 / 3$ Accolnt Executive to gain access.

Group 7 state(s): IL

Conforming Fixed Products - Upto FHLMC Limit

\begin{tabular}{|r|c|c|c|}
\hline & \multicolumn{4}{|c|}{$21-30$ Yr. Fixed (FX30) } \\
\hline & 15 day & $\mathbf{3 0}$ day & $\mathbf{6 0}$ day \\
\hline 5.375 & $(4.700)$ & $(4.575)$ & $(4.450)$ \\
$\mathbf{5 . 2 5 0}$ & $(3.950)$ & $(3.825)$ & $(3.700)$ \\
5.125 & $(3.325)$ & $(3.200)$ & $(2.950)$ \\
5.000 & $(2.825)$ & $(2.700)$ & $(2.450)$ \\
4.875 & $(2.325)$ & $(2.200)$ & $(1.950)$ \\
4.750 & $(1.575)$ & $(1.450)$ & $(1.200)$ \\
4.625 & $(0.825)$ & $(0.700)$ & $(0.450)$ \\
4.500 & $(0.325)$ & $(0.200)$ & 0.050 \\
4.375 & 0.300 & 0.425 & 0.675 \\
4.250 & 1.175 & 1.300 & 1.550 \\
4.125 & 2.675 & 2.800 & 3.175 \\
4.000 & 3.425 & 3.550 & 3.800 \\
3.875 & 4.050 & 4.175 & 4.550 \\
3.750 & 4.925 & 5.050 & 5.300 \\
\hline
\end{tabular}

AGENCY JUMBO LOANS

\begin{tabular}{|c|c|c|c|c|}
\hline \multirow{2}{*}{\multicolumn{5}{|c|}{ AGENCY JUMBO LOANS }} \\
\hline & & & OMSA's ONL & \\
\hline \multirow[b]{2}{*}{ Product } & \multirow[b]{2}{*}{ Purpose } & \multicolumn{3}{|c|}{ LTV \% } \\
\hline & & $<=75$ & $>75 \&<=80$ & $>80$ \\
\hline \multirow{2}{*}{ Fixed Pn } & $\begin{array}{l}\text { Purchase } \\
\text { RT Refi }\end{array}$ & 0.750 & 0.750 & 0.750 \\
\hline & $\begin{array}{l}\text { Castiout } \\
\text { Reti }\end{array}$ & 1750 & $N / A$ & NA \\
\hline \multirow{2}{*}{ Fixed to } & $\begin{array}{l}\text { Purchase } \\
\text { RrT Reff }\end{array}$ & 0.750 & 0.750 & 0.750 \\
\hline & $\begin{array}{l}\text { Cashout } \\
\text { Refi }\end{array}$ & 1.750 & N/A & $N / A$ \\
\hline \multirow{2}{*}{ ARM LO } & $\begin{array}{l}\text { Purchase } \\
\text { R R Ref }\end{array}$ & 1.500 & 2250 & 2250 \\
\hline & $\begin{array}{l}\text { Cashout } \\
\text { Ren }\end{array}$ & 2.500 & N/A & NA \\
\hline
\end{tabular}

At pricing bumps per Conforming products such as Credit ScoreiliTV, Cash Out, Escrow Waiver \& athers apply in addition to above adjustments tho Onyy avaiable for apps priar to 5/17/10. Must Close by 6/13/10

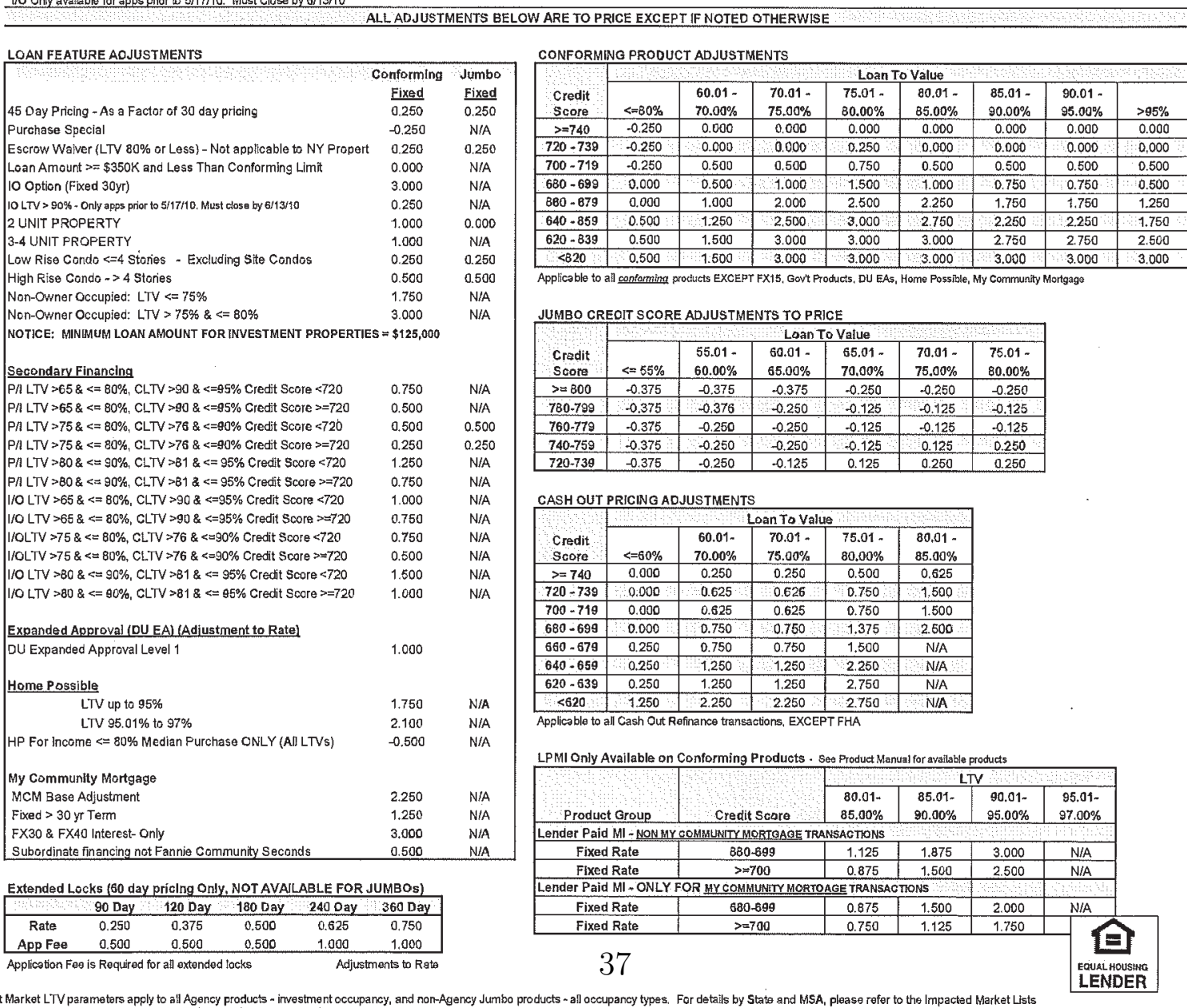

Off Sheet Pricing available: Contact your Account Executive for information FREODIE MAC OPEN ACCESS NOW AVAILABLE - SEE PAGE 5 FOR PRICING AOUUSTMENTS

\begin{tabular}{|r|l|l|l|}
\hline \multicolumn{4}{|c|}{16.20 Yr. Fixed (FX20) } \\
\hline & 15 day & 30 day & 60 day \\
\hline 5.375 & $(4.820)$ & $(4.695)$ & $(4.445)$ \\
$\mathbf{5 . 2 5 0}$ & $(4.195)$ & $(4.070)$ & $(3.820)$ \\
$\mathbf{5 . 1 2 5}$ & $(3.820)$ & $(3.695)$ & $(3.445)$ \\
5.000 & $(3.445)$ & $(3.320)$ & $(3.070)$ \\
4.875 & $(2.945)$ & $(2.820)$ & $(2.695)$ \\
4.750 & $(2.320)$ & $(2.195)$ & $(2.070)$ \\
4.625 & $(1.820)$ & $(1.695)$ & $(1.570)$ \\
4.500 & $(1.445)$ & $(1.320)$ & $(1.070)$ \\
4.375 & $(0.945)$ & $(0.820)$ & $(0.570)$ \\
4.250 & $(0.320)$ & $(0.195)$ & 0.055 \\
4.126 & 3.680 & 3.805 & 4.055 \\
$\mathbf{4 . 0 0 0}$ & 4.180 & 4.305 & 4.680 \\
3.875 & 4.805 & 4.930 & 5.180 \\
3.750 & 5.430 & 5.555 & 5.805 \\
\hline
\end{tabular}

\begin{tabular}{|r|c|c|c|}
\hline \multicolumn{4}{|c|}{$10-15$ Yr. Fixed (FX15) } \\
\hline $\mathbf{5 . 1 2 5}$ & $\mathbf{1 5}$ day & $\mathbf{3 0}$ day & $\mathbf{6 0}$ day \\
\hline $\mathbf{5 . 0 0 0}$ & $(4.520)$ & $(4.395)$ & $(4.270)$ \\
$\mathbf{4 . 8 7 6}$ & $(3.895)$ & $(4.145)$ & $(3.895)$ \\
$\mathbf{4 . 7 5 0}$ & $(3.395)$ & $(3.770)$ & $(3.645)$ \\
$\mathbf{4 . 6 2 5}$ & $(2.895)$ & $(2.770)$ & $(3.145)$ \\
$\mathbf{4 . 5 0 0}$ & $(2.520)$ & $(2.395)$ & $(2.270)$ \\
$\mathbf{4 . 3 7 5}$ & $(2.145)$ & $(2.020)$ & $(1.895)$ \\
$\mathbf{4 . 2 5 0}$ & $(1.645)$ & $(1.520)$ & $(1.395)$ \\
$\mathbf{4 . 1 2 5}$ & $(0.770)$ & $(0.645)$ & $(0.395)$ \\
$\mathbf{4 . 0 0 0}$ & $(0.395)$ & $(0.270)$ & $(0.020)$ \\
$\mathbf{3 . 8 7 5}$ & 0.105 & 0.230 & 0.480 \\
$\mathbf{3 . 7 5 0}$ & 0.730 & 0.855 & 0.980 \\
$\mathbf{3 . 6 2 5}$ & 1.855 & 1.980 & 2.230 \\
$\mathbf{3 . 5 0 0}$ & 2.480 & 2.805 & 2.730 \\
\hline
\end{tabular}

Non-Agency Jumbo Fixed Products - Max Loan Amount \$1MM

\begin{tabular}{|r|l|l|l|}
\hline \multicolumn{4}{|c|}{ Jumbo 16 -30 Yr. Fixed (FJ30) } \\
\hline & $\mathbf{1 5}$ day & $\mathbf{3 0}$ day & $\mathbf{6 0}$ day \\
\hline 6.125 & $(3.255)$ & $(3.130)$ & $(2.880)$ \\
$\mathbf{6 . 0 0 0}$ & $(3.130)$ & $(3.005)$ & $(2.755)$ \\
$\mathbf{5 . 6 7 5}$ & $(3.005)$ & $(2.880)$ & $(2.630)$ \\
$\mathbf{5 . 7 5 0}$ & $(2.505)$ & $(2.380)$ & $(2.130)$ \\
$\mathbf{5 . 6 2 5}$ & $(2.005)$ & $(1.880)$ & $\mathbf{( 1 . 6 3 0 )}$ \\
$\mathbf{5 . 6 0 0}$ & $(1.505)$ & $(1.380)$ & $(1.130)$ \\
$\mathbf{5 . 3 7 5}$ & $(1.130)$ & $\mathbf{( 1 . 0 0 5 )}$ & $(0.755)$ \\
$\mathbf{5 . 2 5 0}$ & $(0.505)$ & $(0.380)$ & $(0.130)$ \\
$\mathbf{5 . 1 2 5}$ & 0.120 & 0.245 & 0.495 \\
$\mathbf{5 . 0 0 0}$ & 0.745 & 0.870 & 1.120 \\
$\mathbf{4 . 6 7 5}$ & 1.370 & $\mathbf{1 . 4 9 5}$ & 1.745 \\
$\mathbf{4 . 7 5 0}$ & 2.120 & 2.245 & 2.495 \\
\hline
\end{tabular}

\begin{tabular}{|c|c|c|c|}
\hline \multicolumn{4}{|c|}{ Jumbo 10-15 Yr. Fixed (FJ15) } \\
\hline & 15 day & 30 day & 60 day \\
\hline 5.625 & $\langle 2.020\rangle$ & $(1.895)$ & (1.645) \\
\hline 5.500 & $(1.895)$ & $(1.770)$ & (1.520) \\
\hline 5.375 & $(1.145)$ & $(1.020)$ & $(0.770)$ \\
\hline 5.250 & $(0.895)$ & $(0.770)$ & $(0.520)$ \\
\hline 5.125 & $(0.645)$ & $(0.520)$ & $(0.270)$ \\
\hline 5.000 & $(0.270)$ & $(0.145)$ & $(0.020)$ \\
\hline 4.875 & 0.355 & 0.480 & 0.605 \\
\hline 4.750 & 0.730 & 0.855 & 0.980 \\
\hline 4.625 & 1.105 & 1.230 & 1.460 \\
\hline 4.500 & 1.480 & 1.605 & 1.855 \\
\hline 4.375 & 2.230 & 2.355 & 2.480 \\
\hline 4.250 & 2.730 & 2.855 & 2.980 \\
\hline
\end{tabular}

Wholesale Rate Sheet For Broker Use Only Rate Sheet Number, Tradtlonal and Table Fund

Combined Broker Compensation (YSP and Broker Fees) Loan Amount $<=\$ 477,000=3.5 \%$ of . Total Loan Amount FIFTH THIRD

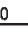
(1) 
Figure 2: The Borrower Opportunity Set

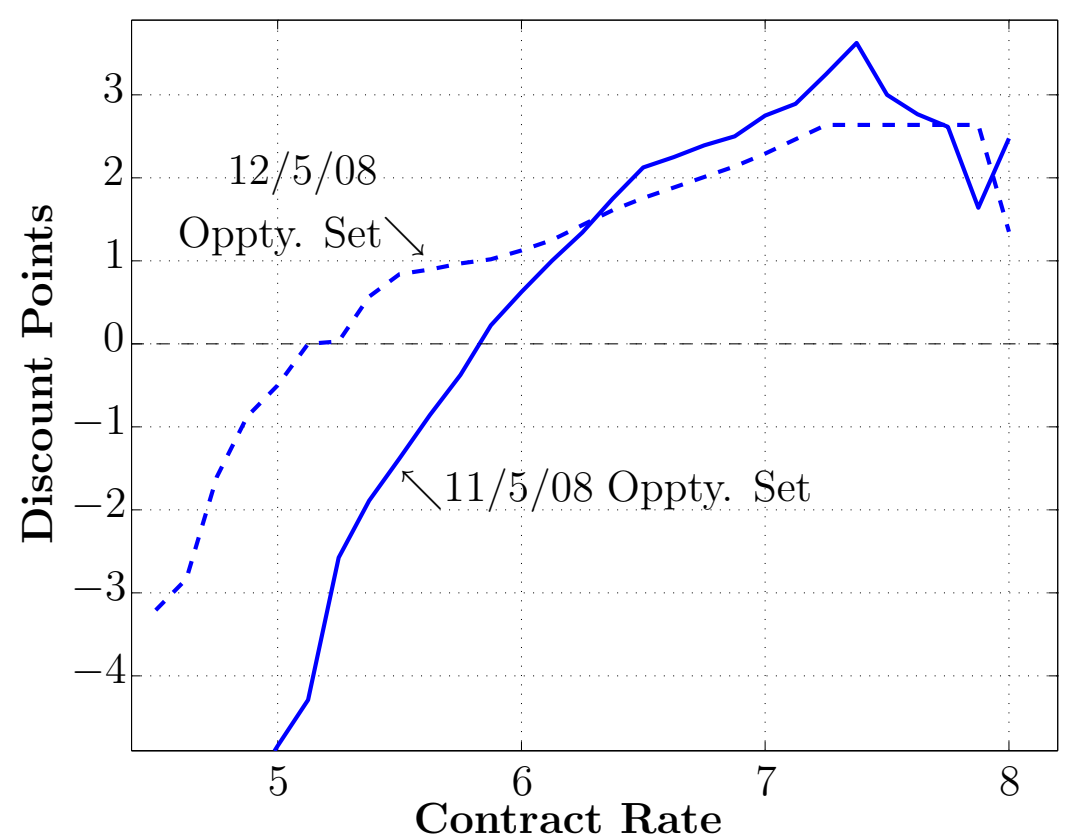

Source: LoanSifter and authors' calculations.

Note: A positive number of discount points means that the borrower or the broker receive money from the lender (with one discount point corresponding to 1 percent of the loan amount), while negative discount points are paid by the borrower to the lender. 
Figure 3: The Effect on Borrower Options of the November 25, 2008 LSAP Program Announcement

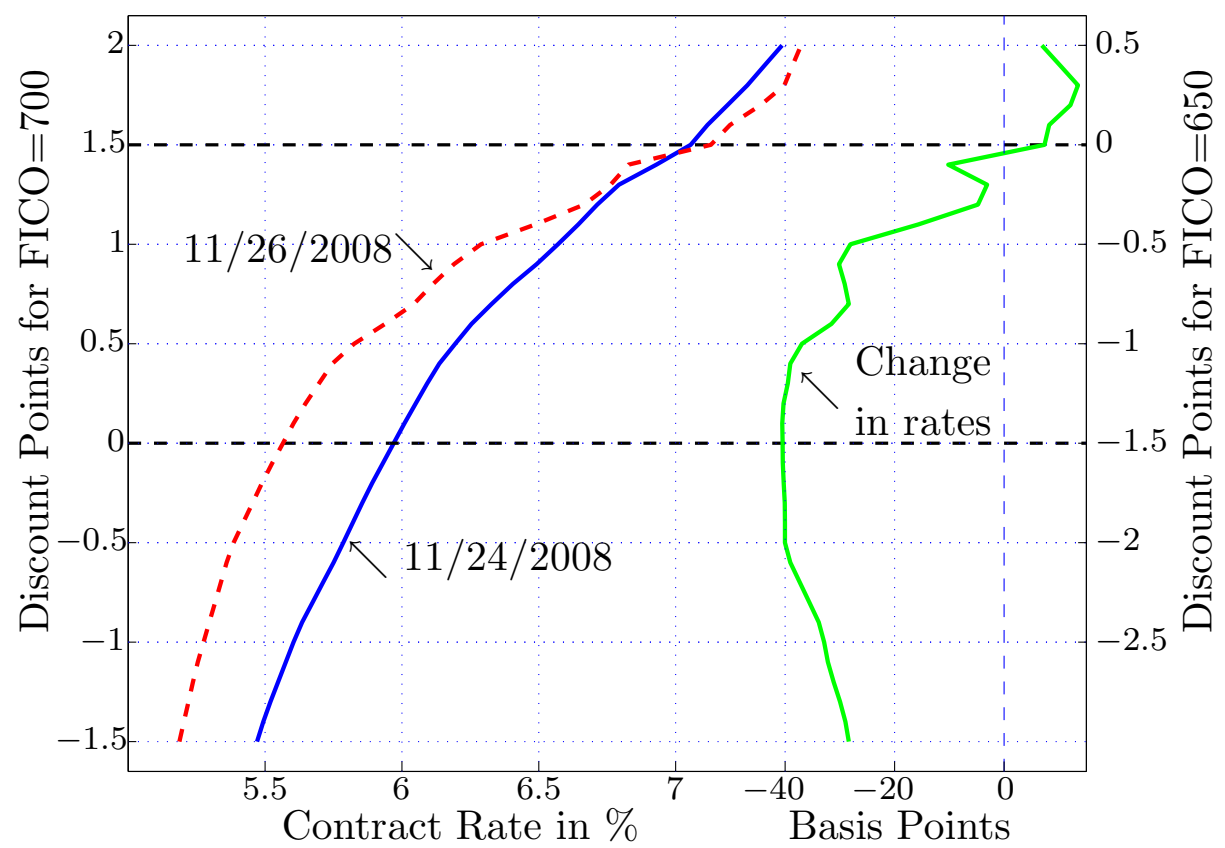

Source: LoanSifter and authors' calculations.

Note: The rates on respective days (left part of the figure) and the rate change between the two days (right part of the figure) for different numbers of points can be read using the left axis for a 700 FICO borrower or using the right axis for a 650 FICO borrower. For instance, reading from the left, a 700 FICO borrower receiving one discount point got a rate of 6.57 on $11 / 24$ and 6.29 on $11 / 26$ for a reduction of 28 bps. Reading from the right, a 650 FICO borrower paying one discount point got a rate of 6.20 on $11 / 24$ and 5.83 on $11 / 26$ for a reduction of $37 \mathrm{bps}$. 
Figure 4: Interest Rates Over the Period Immediately Before and After the Initial Announcement of the LSAP Program on November 25, 2008

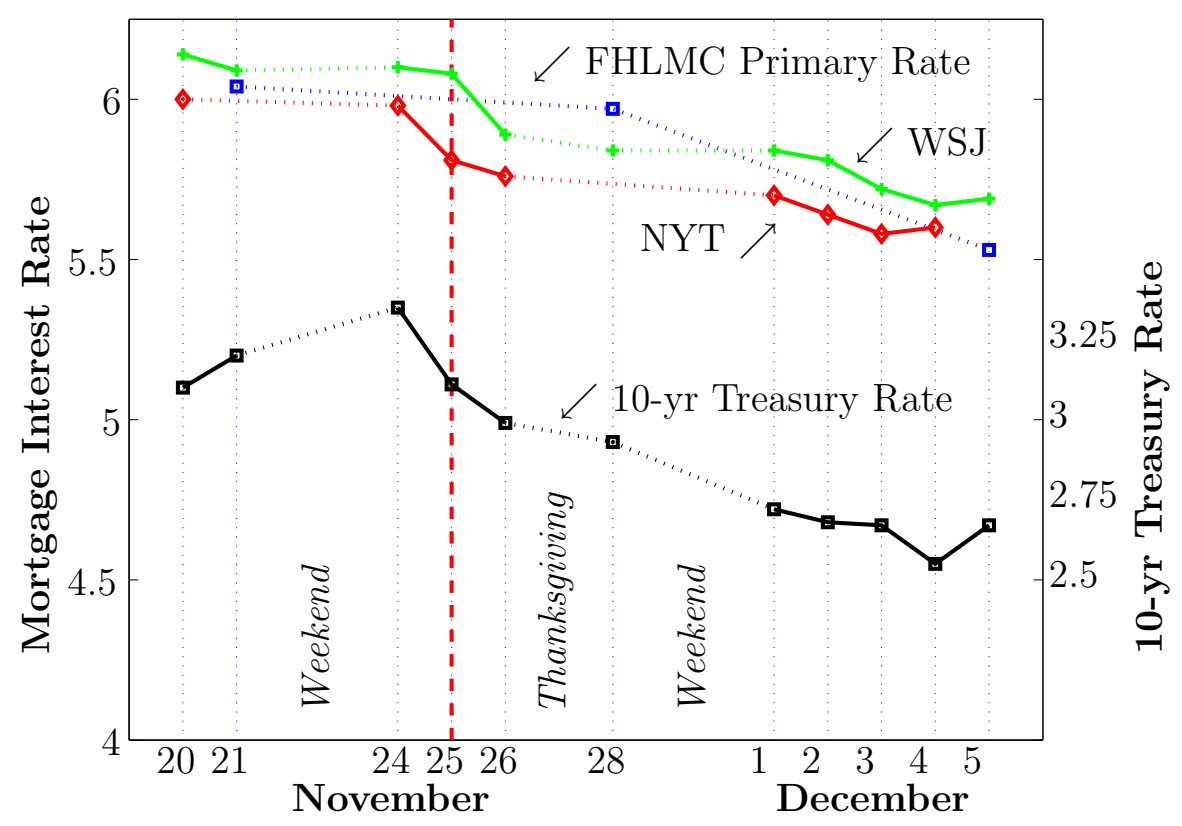

Source: Haver Analytics. 
Figure 5: Number of Points Offered for Different Rates
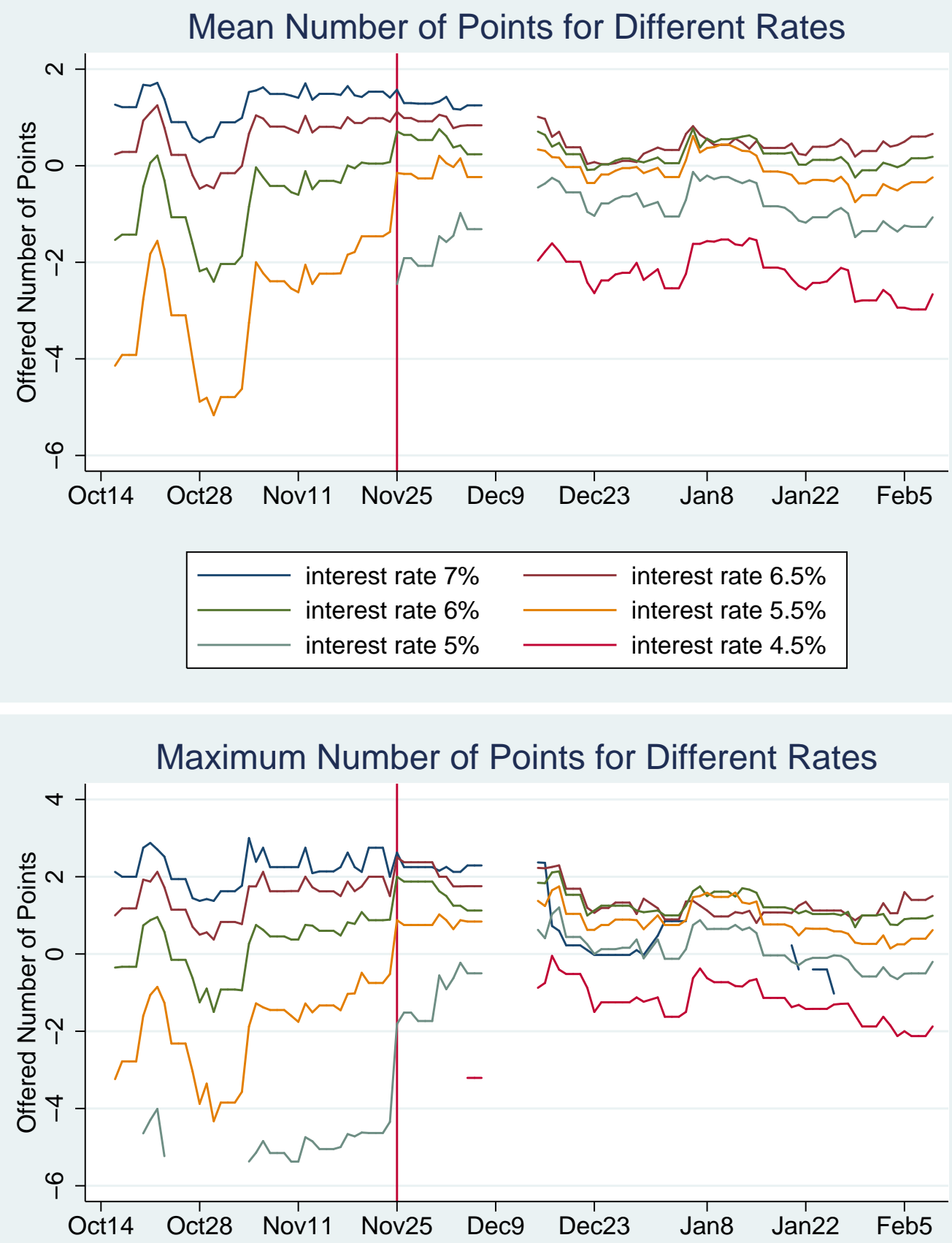

Source: LoanSifter and authors' calculations.

Note: Mean number of points only shown if five or more lenders made an offer at this rate. December 8-14, 2008 are missing from the dataset. 


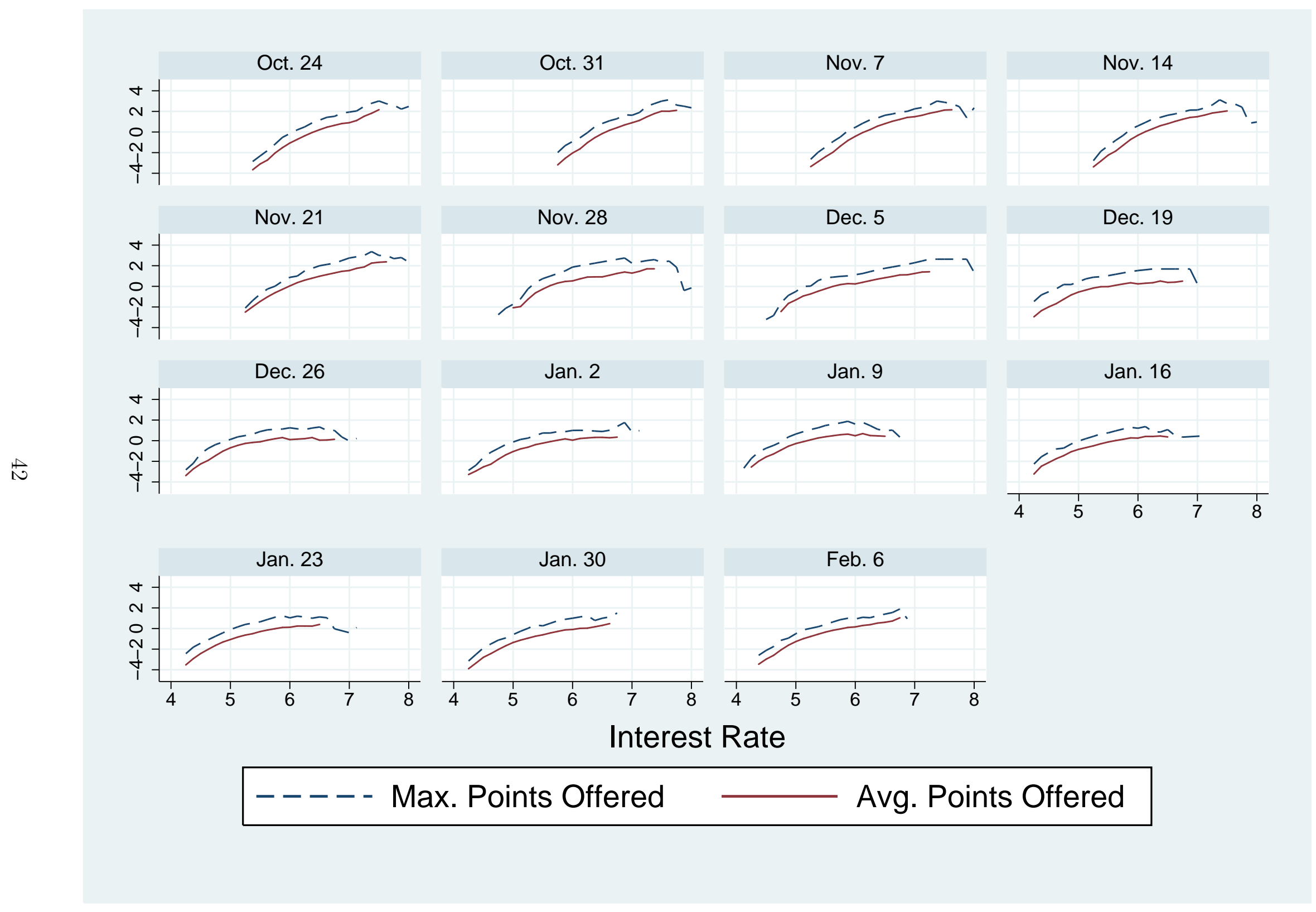


Figure 7: Rates For Borrowers Willing to Pay or Receive One Discount Point
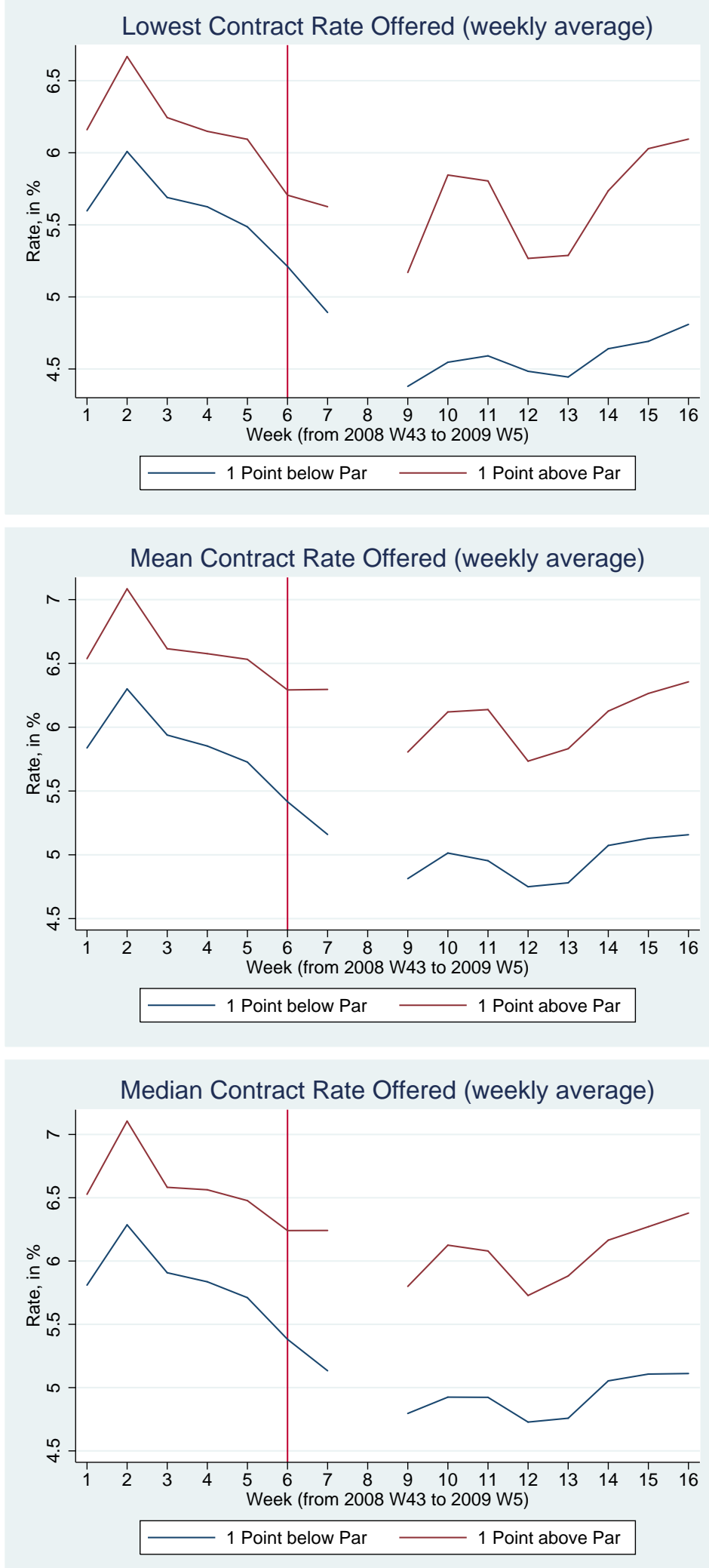

Source: LoanSifter and authors' calculations.

Note: Vertical lines indicate week of November 25, 2008.

The week of December 8, 2008 is missing from the dataset. 
Figure 8: Number of Lenders Who Offer a Loan that Pays One Discount Point

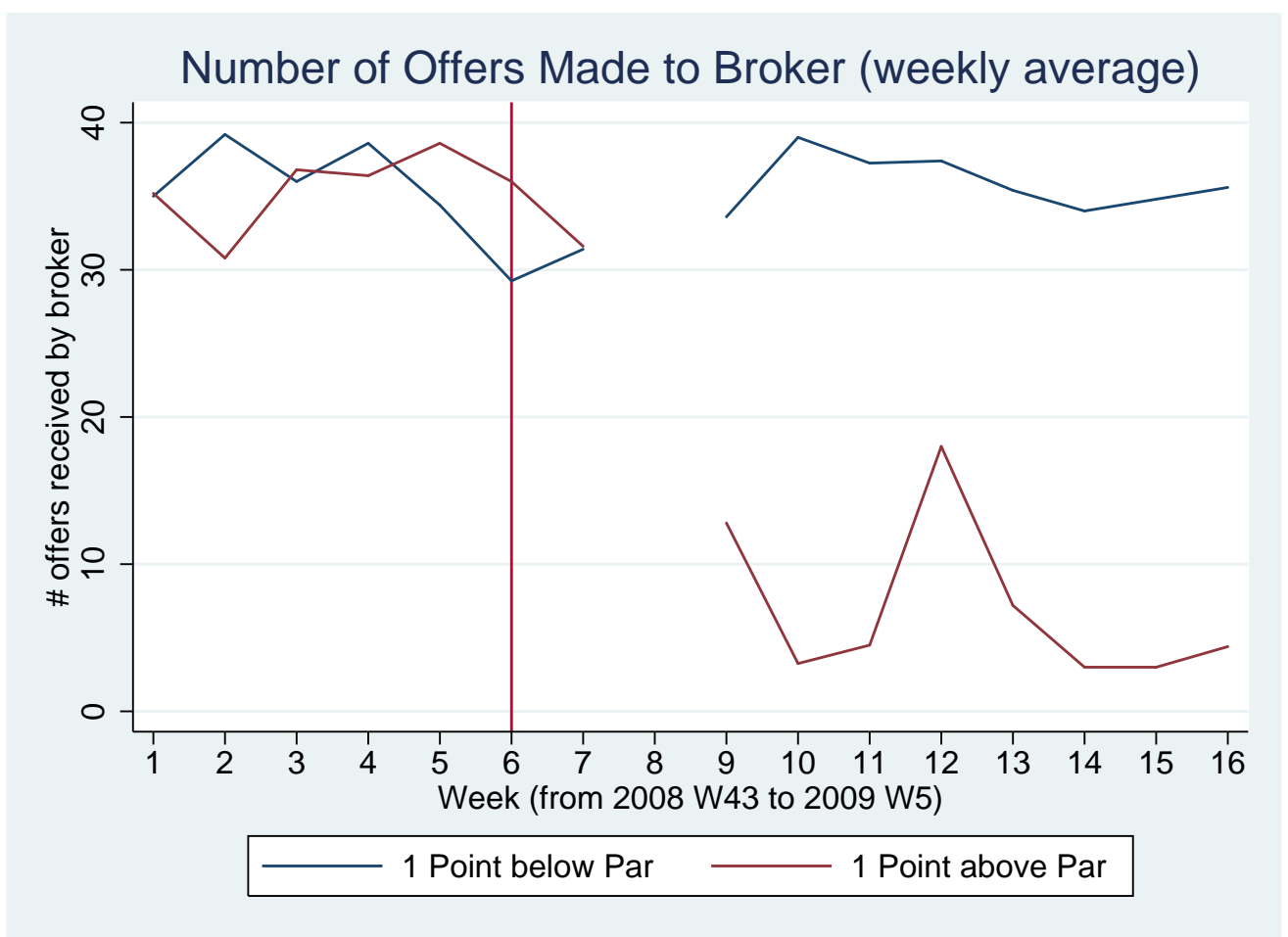

Source: LoanSifter and authors' calculations.

Note: Vertical line indicates week of November 25, 2008. 
Figure 9: Volume of Purchase and Non-purchase Mortgage Originations in LPS
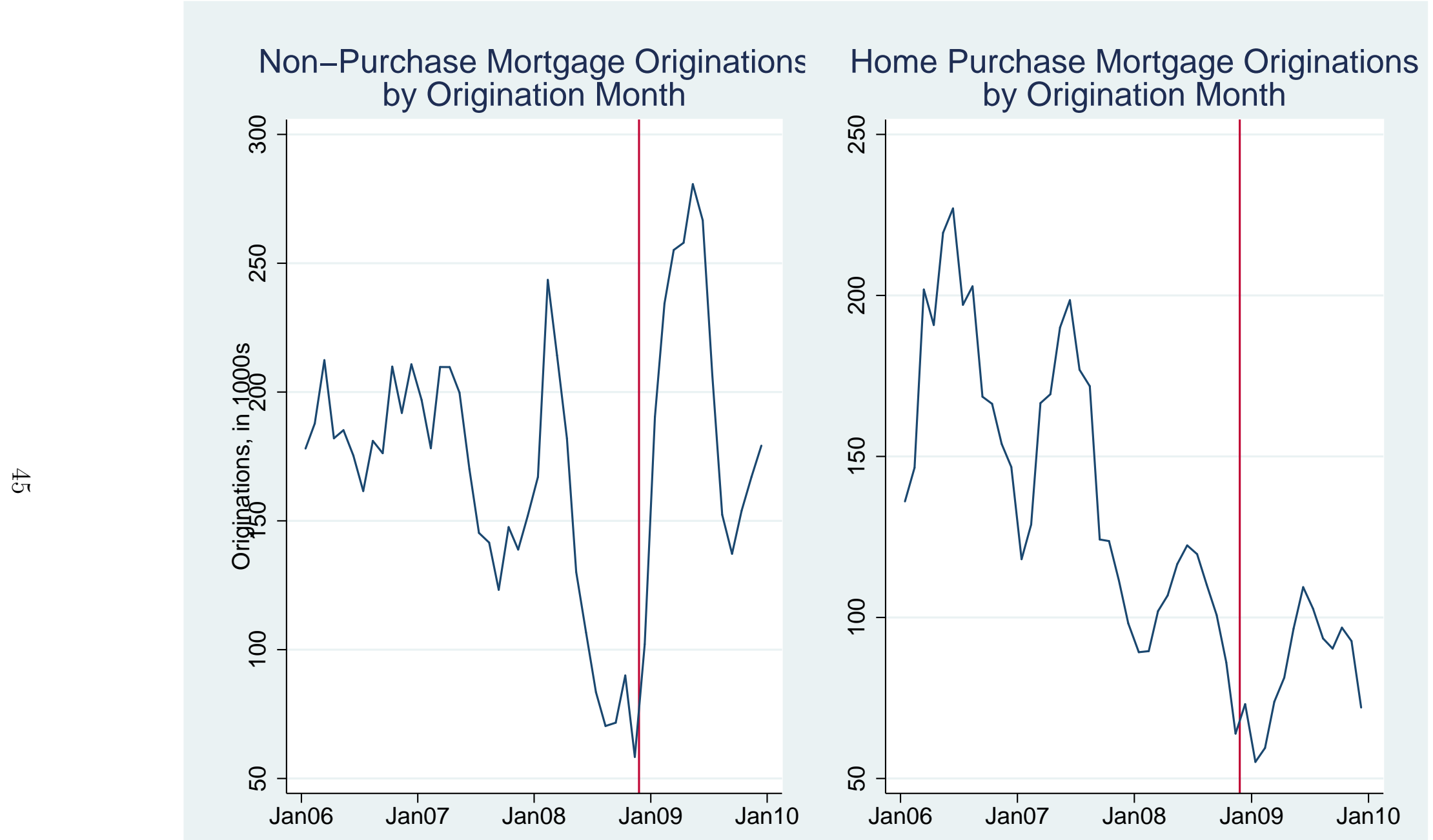

Source: LPS.

Note: Data includes only first-lien mortgages for owner-occupants of 1-4 unit houses or condominiums. Vertical lines indicate week of November 25 , 2008. 
Figure 10: Volume of Mortgage Applications in HMDA

\section{Weekly Mortgage Application Volume, Jan. 2008 to Oct. 2009}
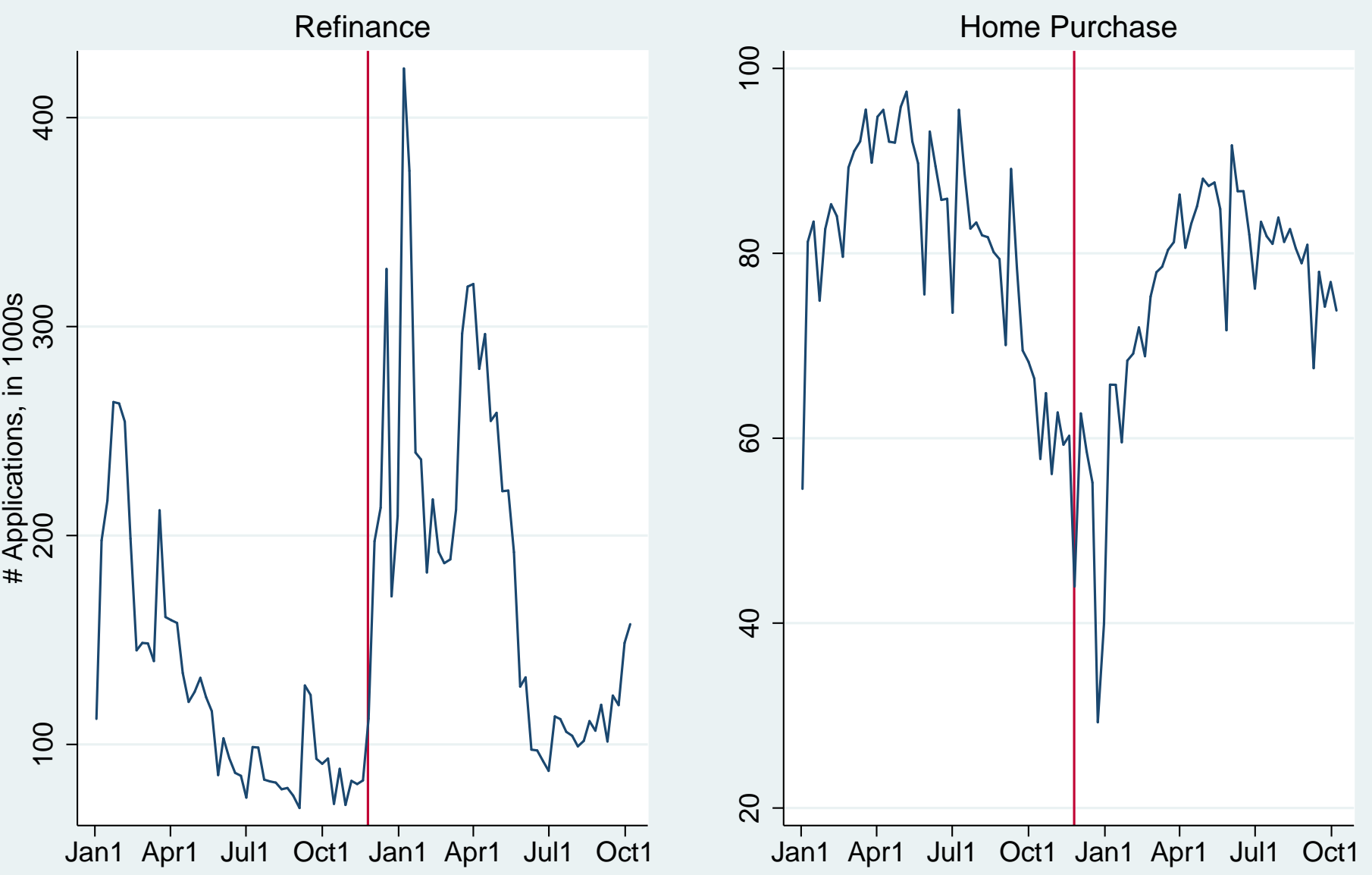

Note: Data includes only first-lien mortgages for owner-occupants of 1-4 unit houses or condominiums. Vertical lines indicate week of November 25 , 2008. 
Figure 11: Volume of Searches in the LoanSifter System

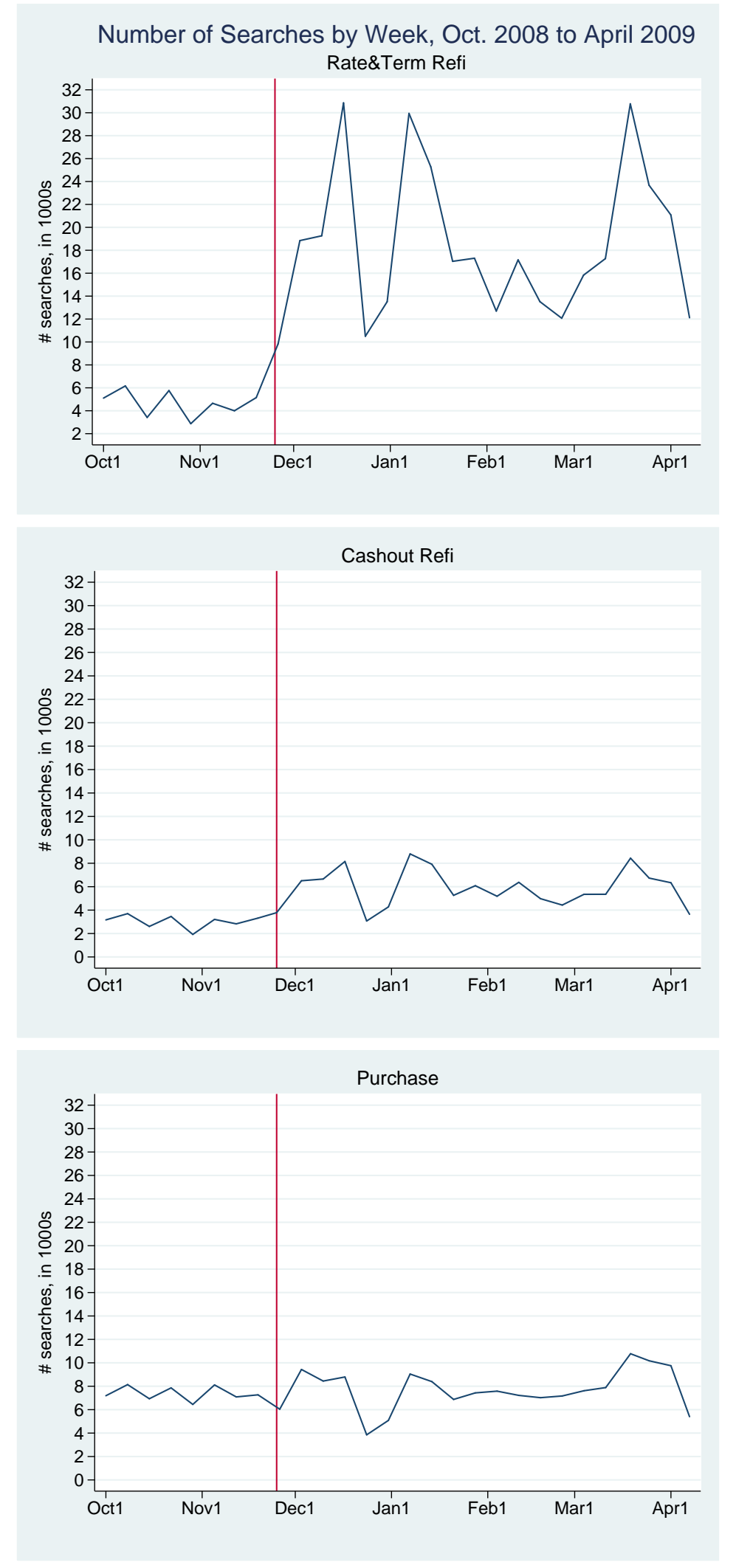

Source: LoanSifter.

Note: Data includes only first-lien mortgages for owner-occupants of 1-4 unit houses or condominiums. Only brokers who first used LoanSifter before October 1, 2008 are considered. Vertical lines indicate week of November 25, 2008. 
Figure 12: Fraction of Refinance Mortgage Applications Originated or Denied

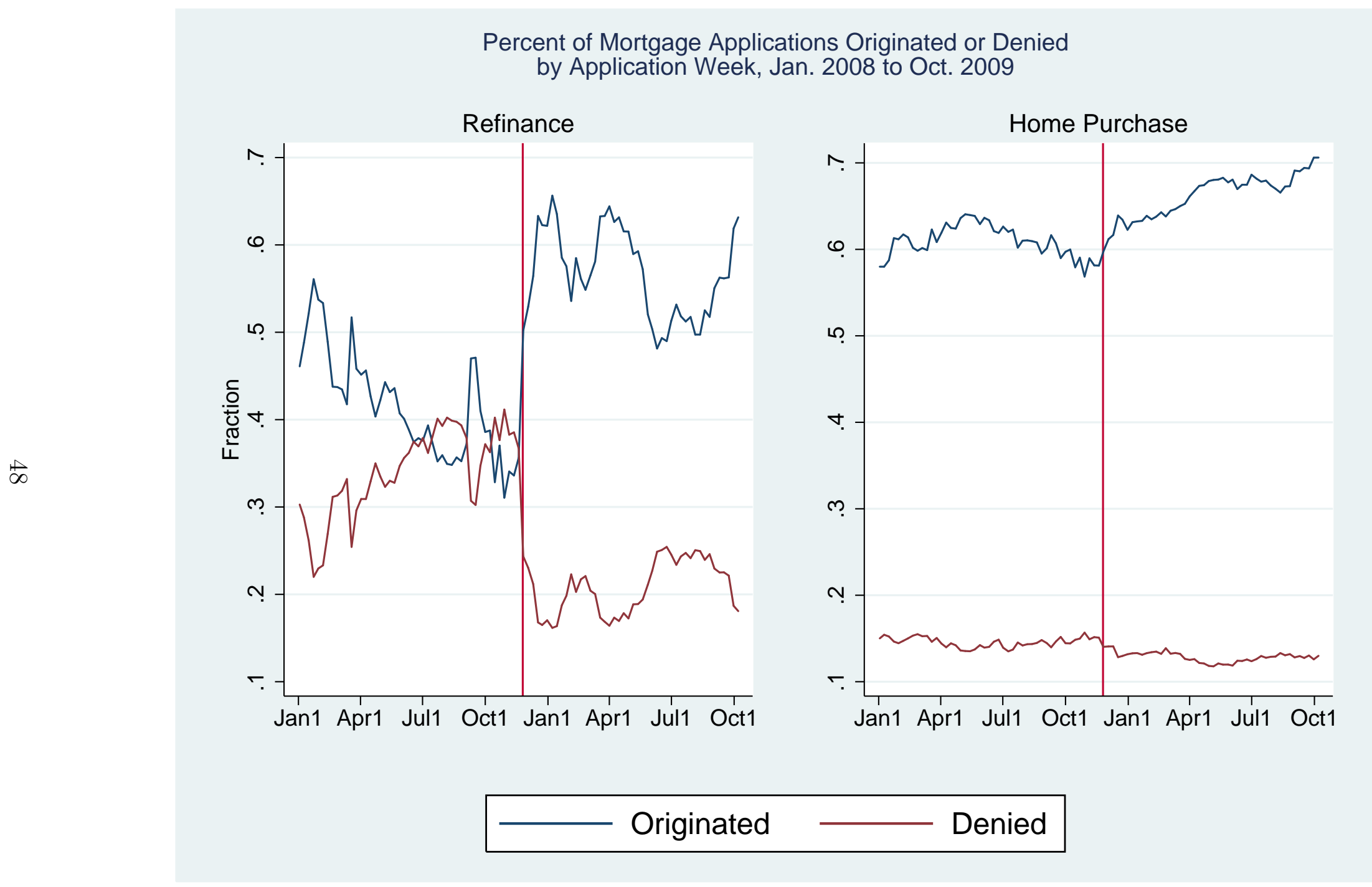

Source: HMDA.

Note: Data includes only first-lien mortgages for owner-occupants of 1-4 unit houses or condominiums. Vertical lines indicate week of November 25 , 2008 . 
Figure 13: Number of Days from Application to Origination or Rejection in HMDA Data

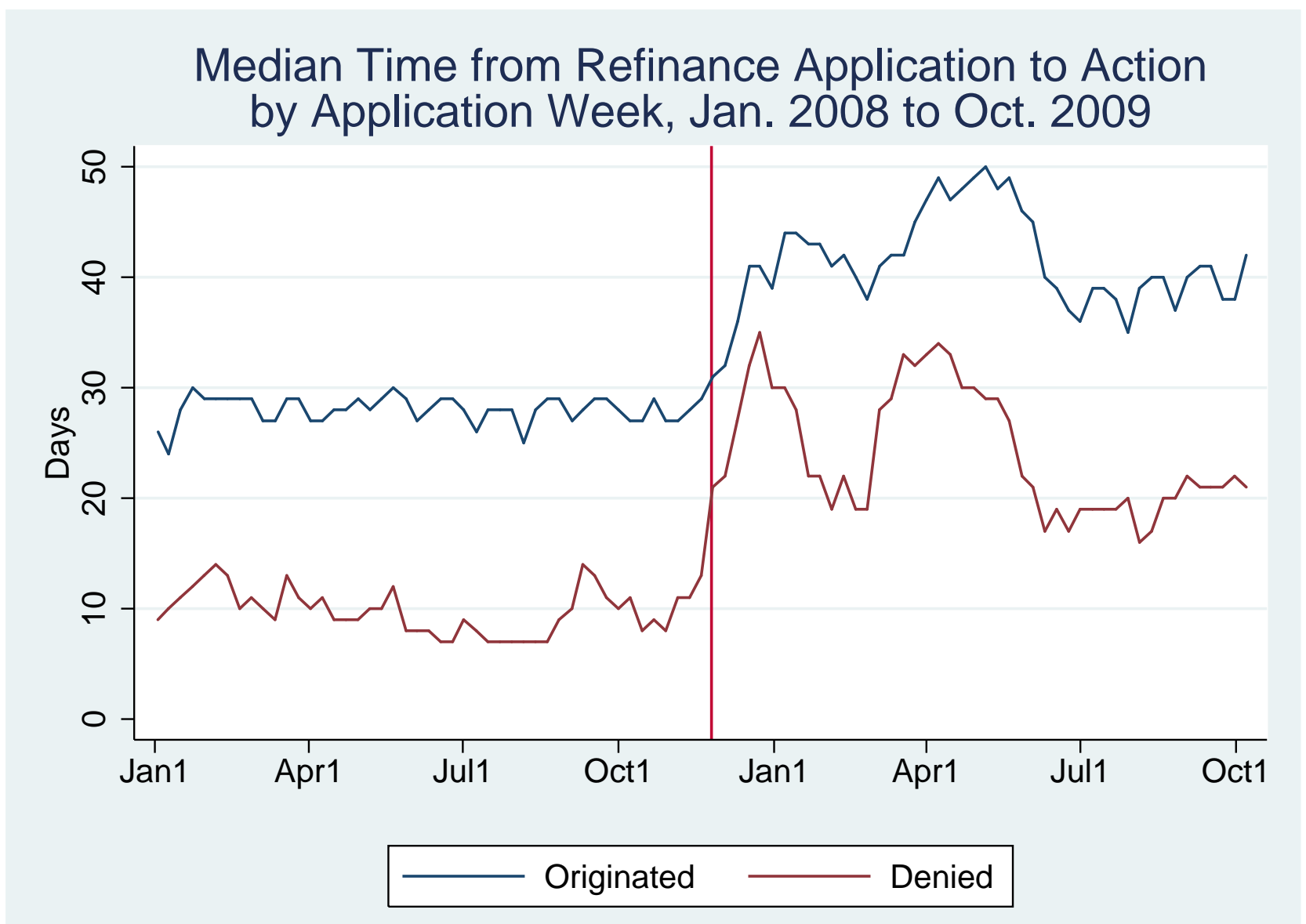

Source: HMDA.

Note: Data includes only first-lien mortgages for owner-occupants of 1-4 unit houses or condominiums. Vertical line indicates week of November 25 , 2008. 
Figure 14: FICO Scores of Purchase and Non-purchase Newly Originated Mortgages in the LPS Dataset

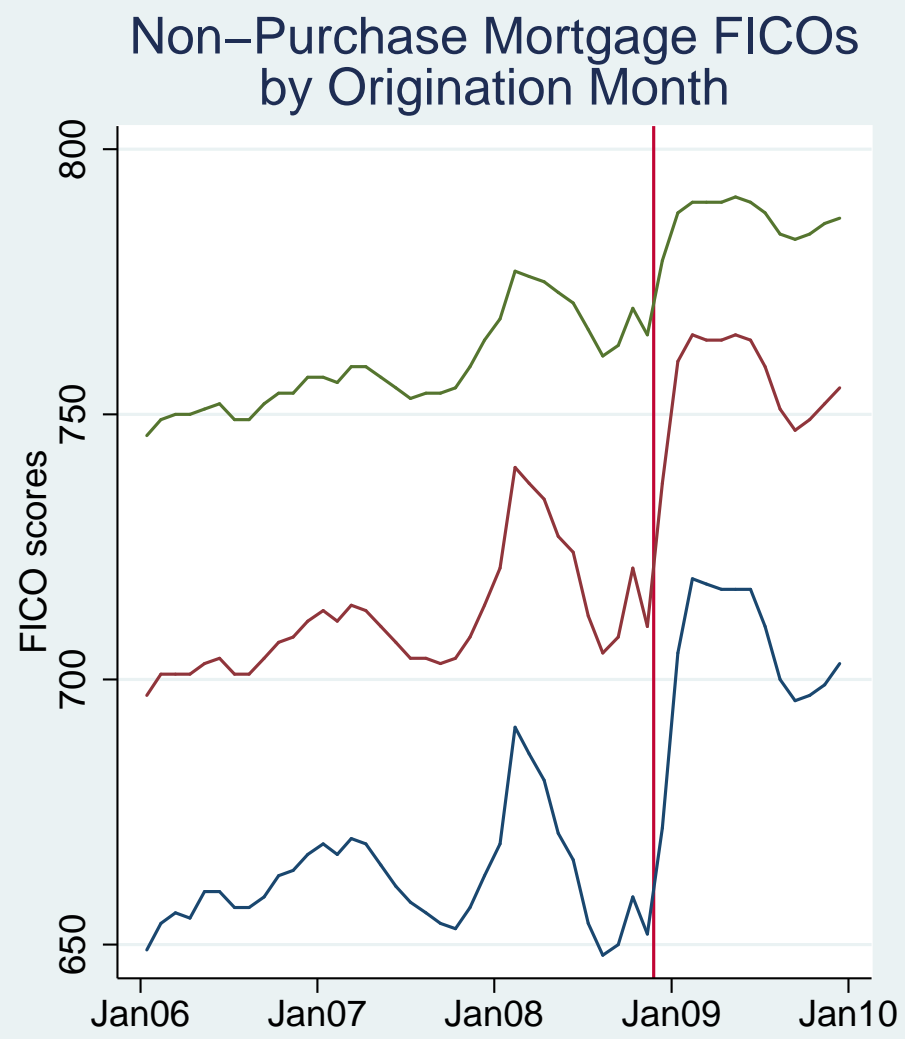

\section{Home Purchase Mortgage FICOs by Origination Month}

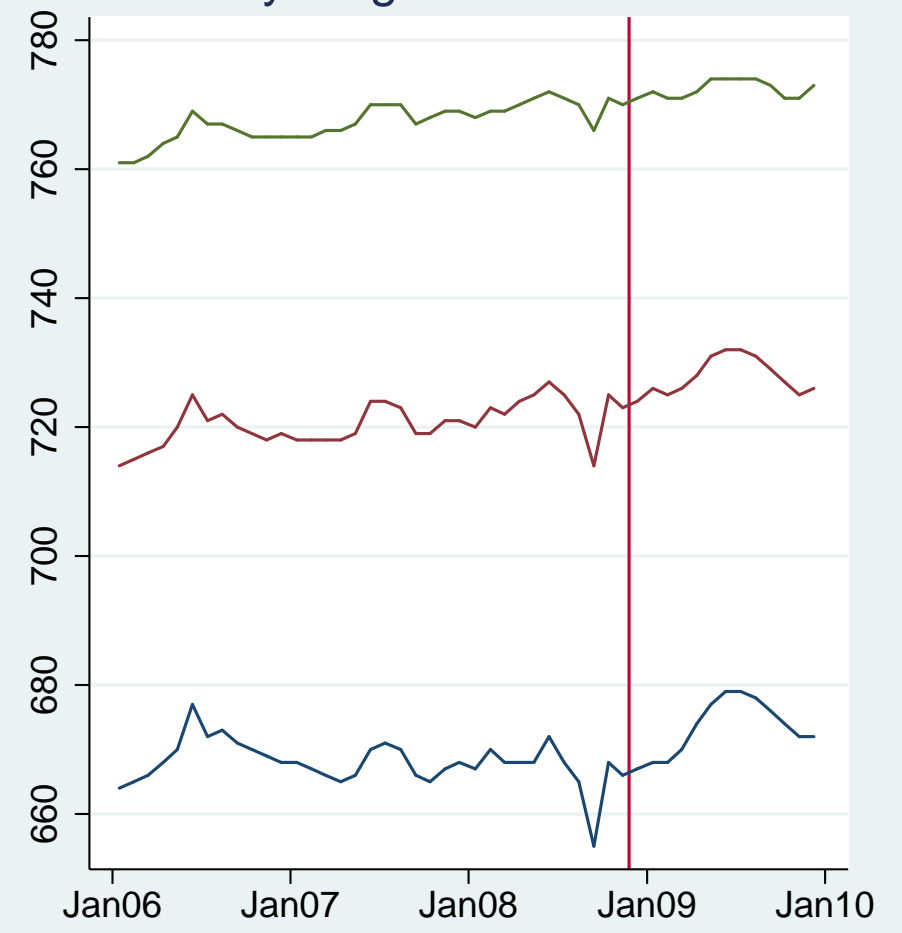

\section{5th percentile} 75th percentile

Median

Note: Data includes only first-lien mortgages for owner-occupants of 1-4 unit houses or condominiums. Vertical lines indicate week of November 25 , 2008. 
Figure 15: Borrower FICO Scores for Originated Refinance Mortgages, by Application Week

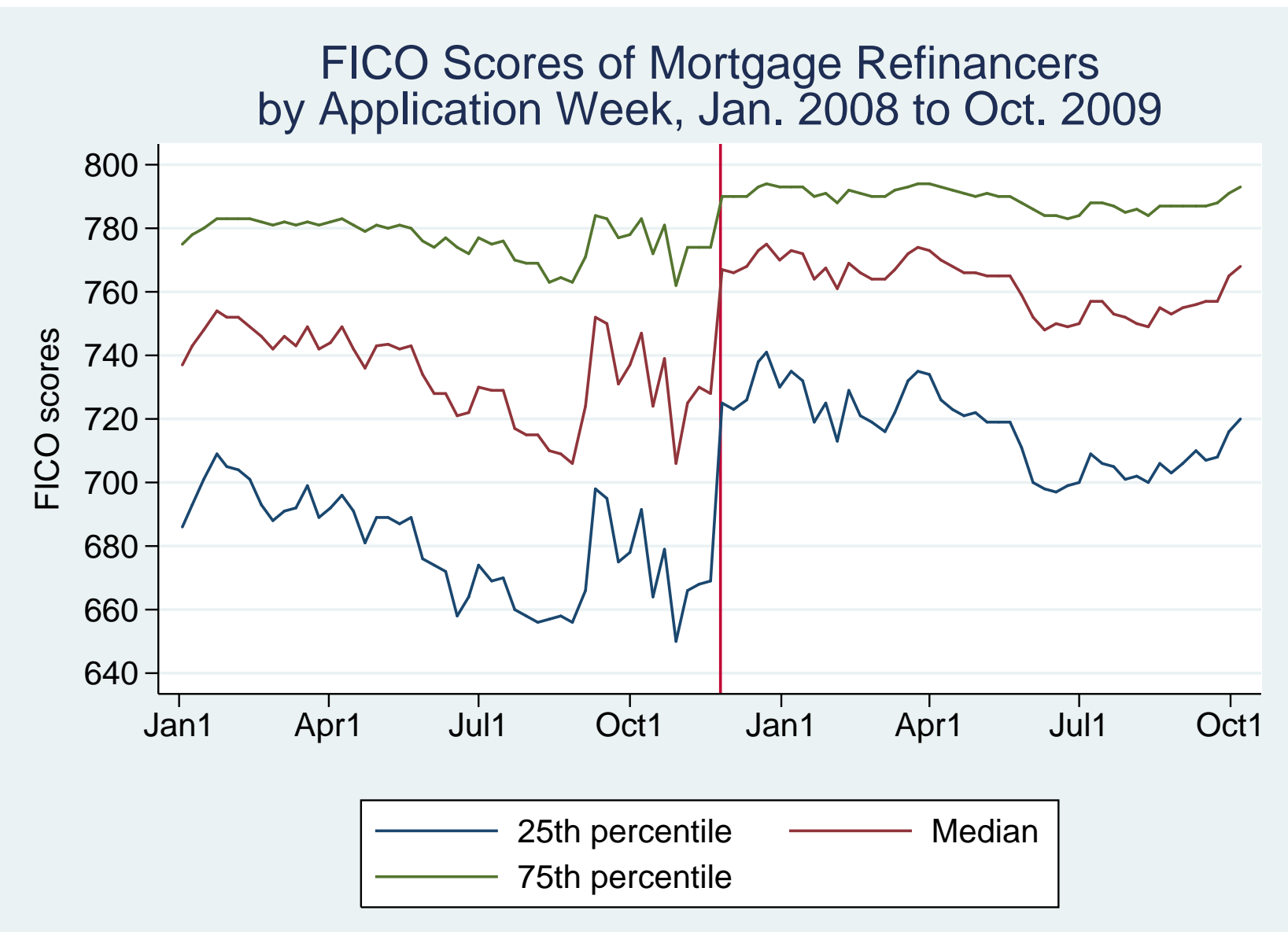

Source: LPS and HMDA.

Note: Data includes only first-lien mortgages for owner-occupants of 1-4 unit houses or condominiums. Vertical line indicates week of November 25, 2008. 
Figure 16: Income Distribution of Refinance Mortgage Applicants

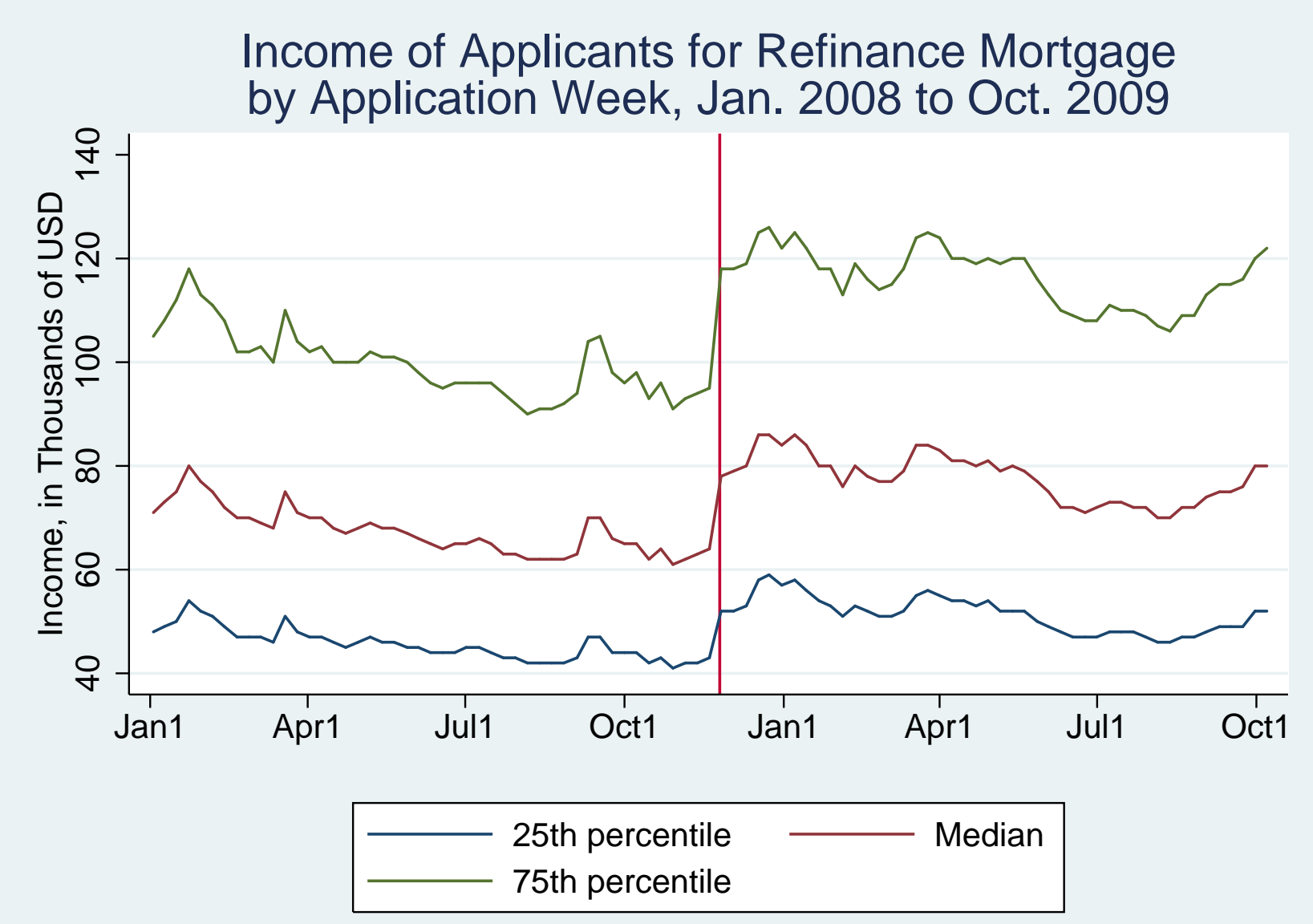

Source: HMDA.

Note: Data includes only first-lien mortgages for owner-occupants of 1-4 unit houses or condominiums. Vertical lines indicate week of November 25, 2008. 
Figure 17: Fraction of Refinance Mortgage Applications Denied, for Different Income Categories

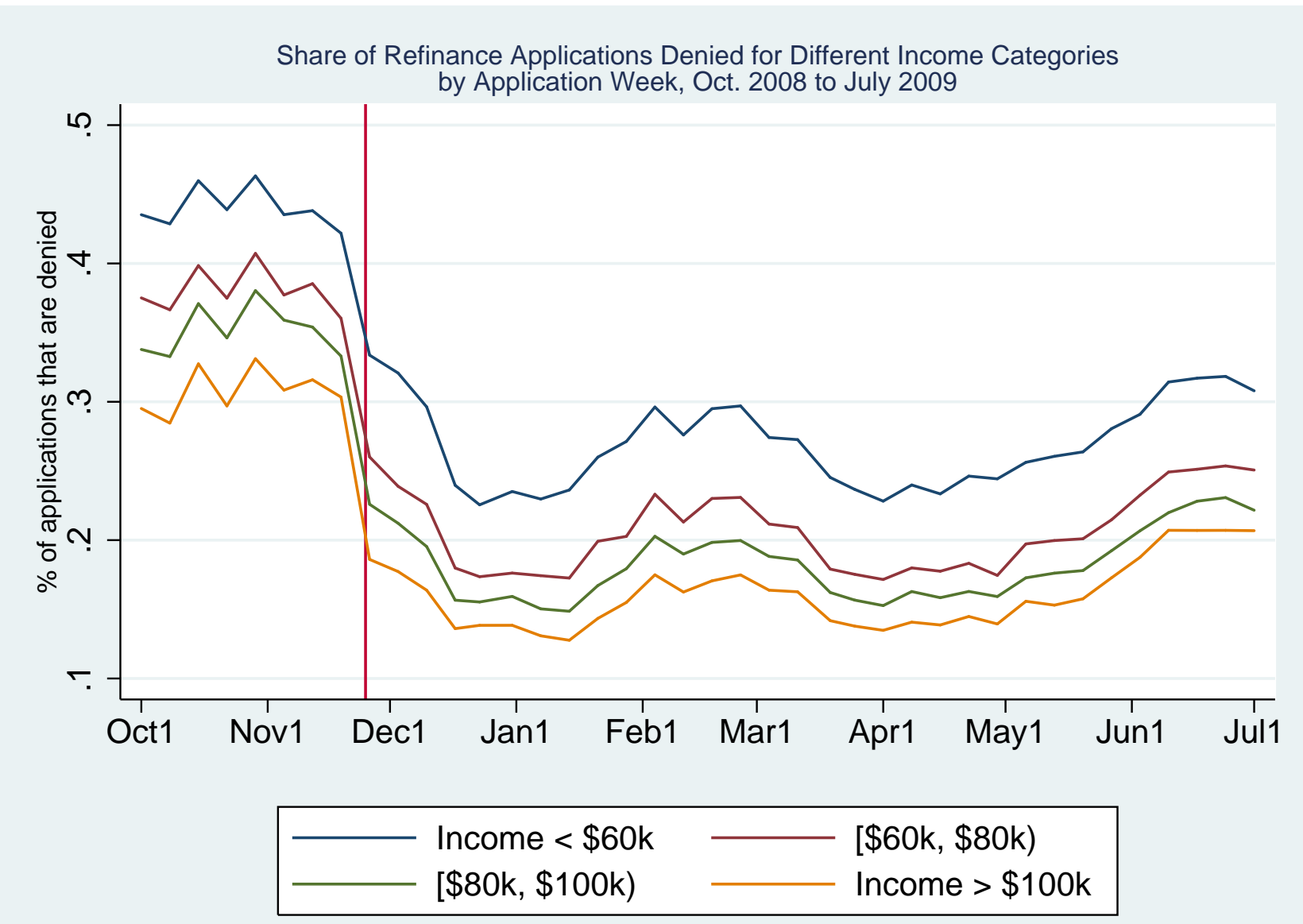

Source: HMDA.

Note: Data includes only first-lien mortgages for owner-occupants of 1-4 unit houses or condominiums. Vertical lines indicate week of November 25, 2008. 
Figure 18: FICO Score Distribution of Searches in LoanSifter for Refinance Mortgages

\section{FICO Score Distribution of Loansifter Searches by Week, Oct. 2008 to April 2009}
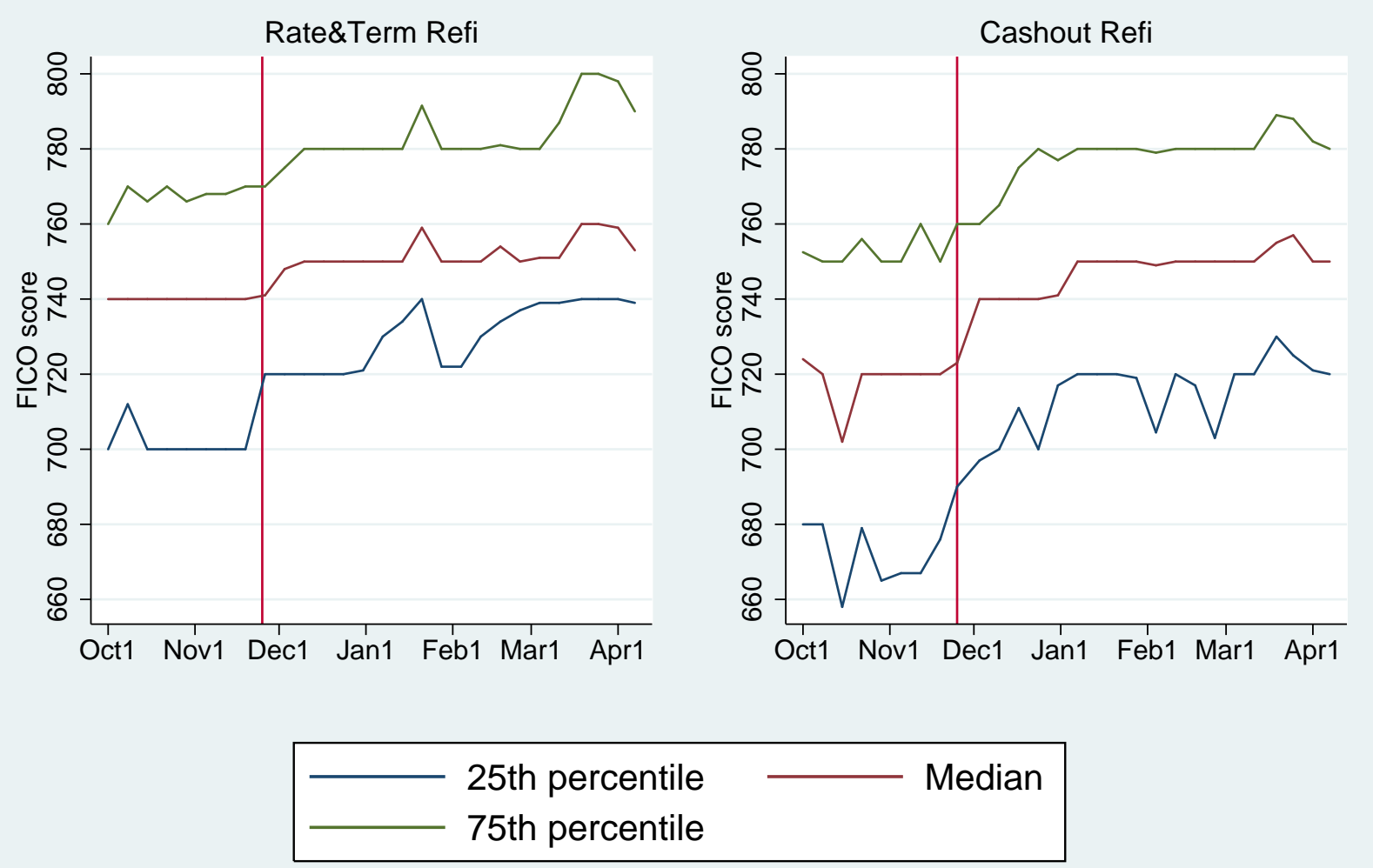

Source: LoanSifter.

Note: Data includes only first-lien mortgages for owner-occupants of 1-4 unit houses or condominiums. Vertical lines indicate week of November 25, 2008. 
Figure 19: Number of Originated Conventional Non-purchase Mortgages in 2008 and 2009, by FICO Score Value

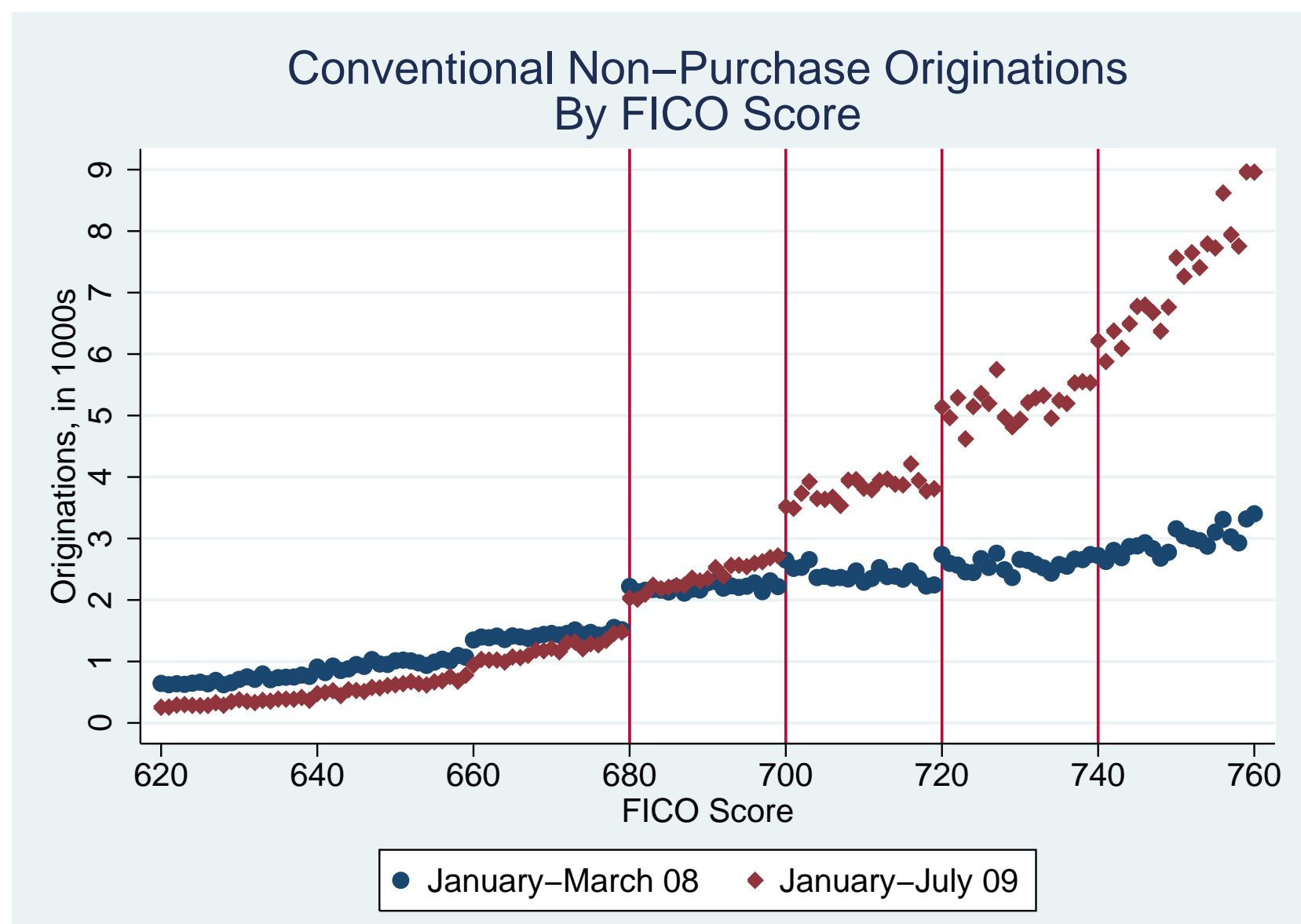

Source: LPS.

Note: Data includes only first-lien mortgages for owner-occupants of 1-4 unit houses or condominiums. Vertical lines indicate some of the cut-off values for Loan-Level Price Adjustments (see table 4). 
Figure 20: Fannie Mae MBS Prices for Different Coupons

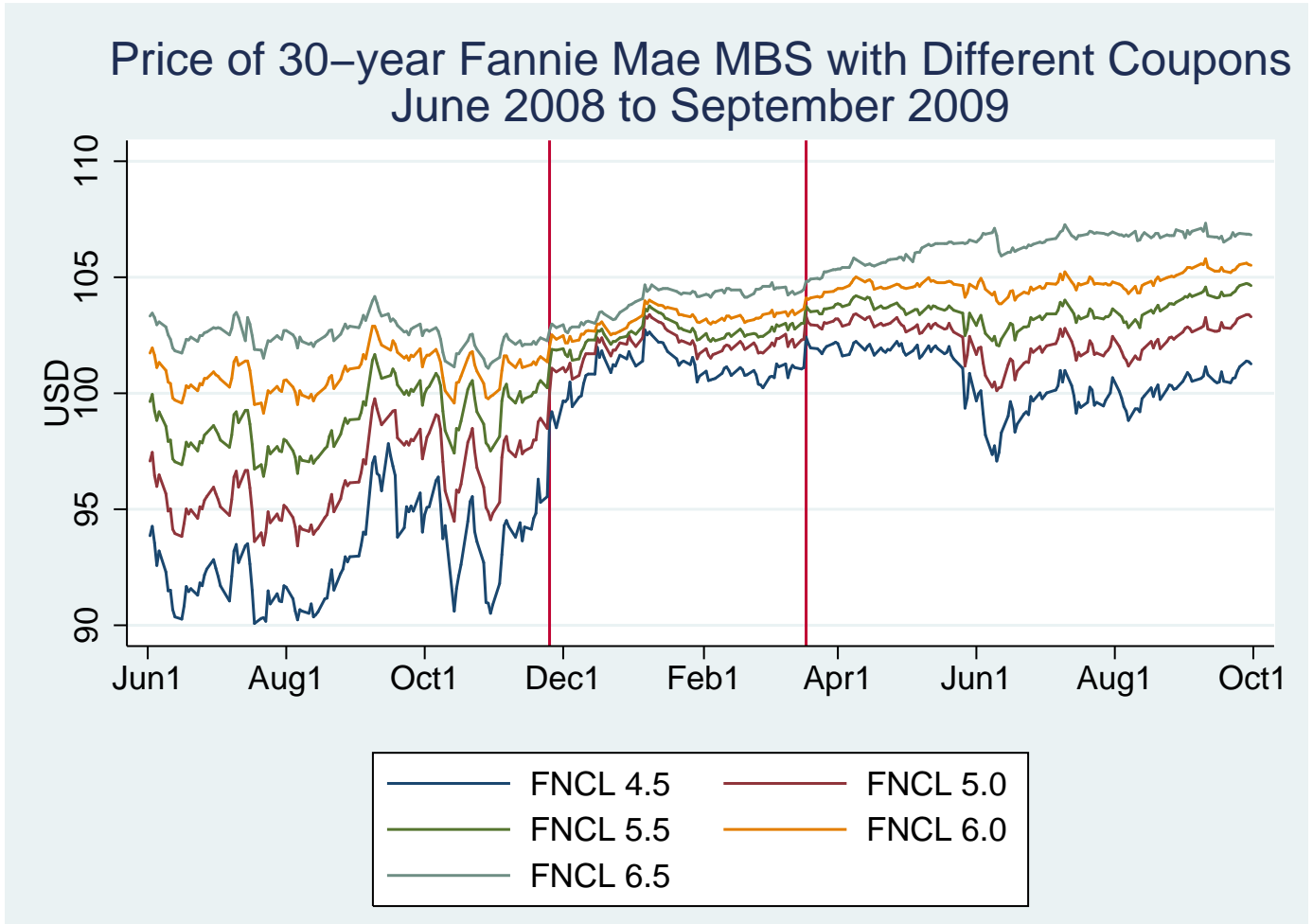

Source: Bloomberg.

Note: Vertical lines indicate the initial LSAP announcement on November 25, 2008 and the extension announcement on March 18, 2009. 